\title{
PEIXES E PESCA NA BACIA DO RIO DOCE, UMA ANÁLISE BIBLIOMÉTRICA
}

\author{
FISH AND FISHERIES ON RIO DOCE WATERSHED, A BIBLIOMETRIC ANALYSIS
}

\section{Mayra Jankowsky ${ }^{1 *}$, Raphaela Martins de Carvalho², Vanielle Aparecida do Patrocinio Gomes $^{3}$ \& Rodrigo Randow de Freitas ${ }^{4}$}

\author{
${ }^{1}$ Instituto de Pesca de São Paulo. ${ }^{2,3}$ Fundação de Desenvolvimento da Pesquisa do Agronegócio. ${ }^{4}$ Centro \\ Universitário Norte do Espírito Santo da Universidade Federal do Espírito Santo. \\ 1*mayra.jankowsky@gmail.com ${ }^{2}$ rapha_carvalhoo@ hotmail.com ${ }^{3}$ vaniellea.gomes@hotmail.com \\ ${ }^{4}$ rodrigo.r.freitas@ufes.br
}

\section{ARTIGO INFO.}

Recebido em: 23.12.2020

Aprovado em: 25.01.2021

Disponibilizado em: 05.02.2021

\section{Palavras-Chave:}

Biodiversidade, impactos ambientais, rompimento de barragem de rejeitos

\section{KEYWORDS:}

Biodiversity, environmental impacts, tailings dam failure

\section{*Autor Correspondente: Jankowsky, M.}

\section{RESUMO}

A Bacia do Rio Doce é reconhecida como hotspot para conservação com elevada diversidade biológica e sociocultural. A região ficou marcada pelo rompimento da barragem do Fundão, em 2015. Nesse contexto, realizou-se avaliação bibliométrica das publicações na Bacia do Rio Doce, desde 1969 a julho de 2020, verificando as mudanças ocorridas, principais áreas estudas e lacunas de conhecimento. A análise da Bacia do Rio Doce foi feita de forma quantitativa, enquanto a análise das publicações referentes à ictiofauna e pesca foi realizada de forma qualitativa. Os resultados mostram a mudança de foco entre as pesquisas realizadas na Bacia do Rio Doce, após o rompimento da barragem. Em relação a ictiofauna, evidencia-se o grande número de espécies descobertas no alto e médio rio Doce, bem como o impacto da introdução de espécies exóticas, em contraste com escassas pesquisas sobre a atividade pesqueira. Inversamente, nos sistemas costeiros e estuarinos, há pesquisas sobre atividades pesqueiras, em contraponto com o baixo número de pesquisas sobre diversidade da ictiofauna. Há consenso sobre a gravidade do dano causado pelo rompimento da barragem do Fundão, conforme os estudos relativos à contaminação revelam os efeitos danosos à ictiofauna em toda a extensão da Bacia do Rio Doce, bem como nos sistemas costeiros e estuarinos. Por fim, o impacto sobre a pesca é apontado ligado à contaminação, proibição de pesca, desvalorização do pescado, dificuldade de reparação e reconhecimento do dano causado. Fatores agravados pelas baixas condições sociais, falta de infraestrutura, e baixo investimento na pesca artesanal em detrimento de grandes obras.

\begin{abstract}
Rio Doce watershed is recognized as hotspot with high biological and sociocultural diversity. Region is recognized by the collapse of the Fundão dam, in 2015. In this context, bibliometric evaluation of publications in the Rio Doce watershed was carried out, from 1969 to June 2020, verifying the changes that occurred, main study areas and gaps in knowledge. The analysis was done in a quantitative way, while the analysis of the publications related to ichthyofauna and fisheries was carried out in a qualitative way. The results show a change in focus among the research carried out in the Rio Doce watershed, after the dam burst. In relation to ichthyofauna, it is notorious the large number of species discovered in the upper and middle Rio Doce, as well as the impact of the introduction of alien species, in contrast to little research on fishing. Conversely, in the coastal region, there are researches on fishing, in contrast to low research number about diversity. There is consensus on the severity of damage caused by Fundão dam rupture, as the studies related to contamination reveal the harmful effects on ichthyofauna throughout the length of the Rio Doce watershed, as well as in the coastal zone. Finally, the impact on fishing is pointed out linked to contamination, fishing prohibition, devaluation of fish, difficulty in repair and recognition of the damage caused. Factors aggravated by low social conditions, lack of infrastructure, and low investment in artisanal fishing to the detriment of major works.
\end{abstract}




\section{INTRODUÇÃO}

A Bacia do Rio Doce encontra-se inserida no bioma Mata Atlântica, o qual devido ao alto endemismo, riqueza de espécies e elevado grau de ameaça foi reconhecido, em 2000, como um hotspot para conservação ambiental no mundo (Myers, Mittermeier, Mittermeier, da Fonseca, \& Kent, 2000), e mesmo com algumas revisões de quais seriam os hotspots mundiais, se manteve como prioritário para a conservação (Marchese, 2015). Entre seus atributos ambientais, se destaca o sistema de lagoas, que fomentou a criação do Parque Estadual do Rio Doce (PERD) e posteriormente, foi reconhecido devido sua importância como sítio Ramsar (MMA, 2020).

Além da importância ambiental, a região possui quatro territórios indígenas reconhecidos, o TI Krenak (Urquiza \& Rocha, 2019), três territórios indígenas tupiniquins-guaranis (FUNAI, 2020), e três territórios quilombolas e pescadores artesanais, mostrando assim uma diversidade cultural pujante e presente na região.

Entretanto, a região ficou em evidência após o rompimento da barragem de rejeitos de Fundão, Mariana, em 5 de novembro de 2015. Pertencente à empresa de mineração Samarco, controlada pela BHP Billiton Brasil Ltda. e pela Vale S.A., o rompimento liberou 34 milhões de metros cúbicos de rejeitos da extração e processamento de ferro, ocasionando a morte de dezenove pessoas e um dos maiores desastres ambientais presenciados no país, quiçá mundialmente (A. T. Lima et al., 2020; Losekann, 2017). Entre os danos ambientais, destaca-se a morte por asfixia de 14 toneladas de macro fauna aquática, especialmente peixes, e entre os grupos impactados, as comunidades locais, no entorno da calha do rio Doc, bem como os pescadores, estão entre os grupo mais afetados (A. T. Lima et al., 2020, 2021). Desde então, observa-se que os impactos socioambientais causados vêm sendo alvo de diversos estudos, nas diferentes áreas de conhecimento.

Nesse contexto, este estudo objetivou uma análise bibliométrica das publicações oficiais e disponíveis na área de estudo da Bacia do Rio Doce, buscando verificar as mudanças ocorridas, potencialidades, principais áreas estudas e lacunas de conhecimento. A análise foi realizada de forma quantitativa, enquanto as publicações referentes à ictiofauna e pesca foi realizada de forma qualitativa. Esse recorte foi adotado pois, ainda que haja uma grande diversidade de peixes de água doce, com mais de 80 espécies (Viana, 2017), o Registro Geral de Pesca mostra a presença de poucos pescadores no alto e médio Rio Doce (MAPA, 2020). Somado a este fato, no baixo Rio Doce a pesca nas lagoas e porção marinha tem sido relatada como de grande relevância (Rocha, Santos, \& Freitas, 2018). Dessa forma, a análise qualitativa permitiu um melhor entendimento do conhecimento sobre a ictiofauna regional e sua participação na atividade pesqueira.

\section{Metodologia}

A análise bibliométrica surge como uma disciplina que utiliza variados métodos, procedimentos, metodologias, dentre outros, associados ao uso de ferramentas estatísticas para entender comportamentos de fenômenos, tendo por base diferentes trabalhos e fontes científicas (Mishra, Gunasekaran, Papadopoulos, \& Childe, 2016; Bartolini, Bottani, \& Eric, 2019). 
Comparativamente a revisão literária tradicional, este tipo de análise pode ser considerada inovadora, devido ao amplo espectro de alternativas e julgamentos que podem ser empregados (Merigó, Pedrycz, Weber, \& de la Sotta, 2018) (Figura 1).

Figura 1. Etapas e desdobramento metodológico aplicado no presente estudo bibliométrico.

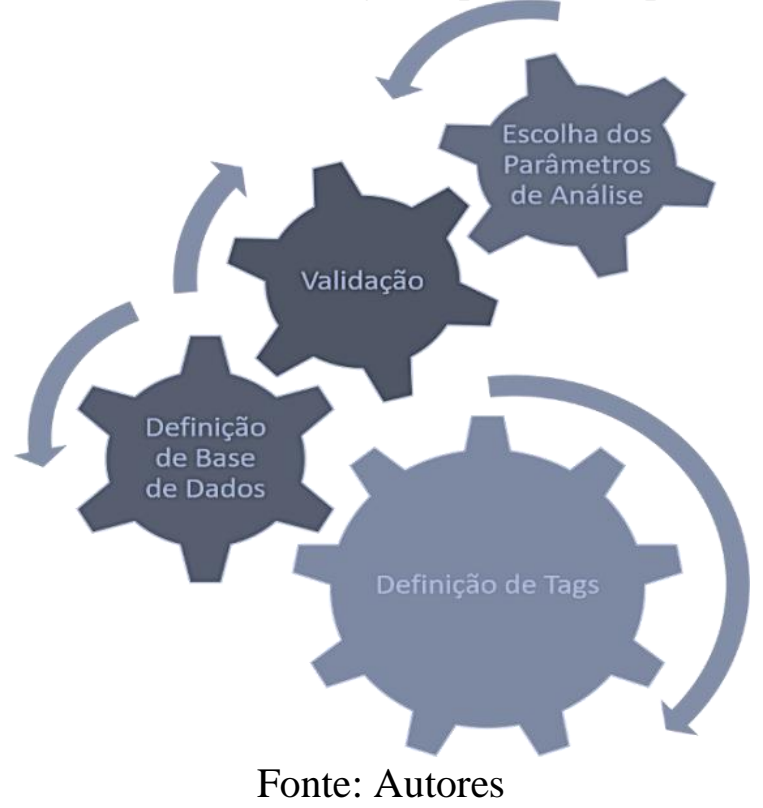

A definição das "tags" ou palavras-chave buscou caracterizar todos os aspectos da Bacia Hidrográfica do Rio Doce, permitindo uma visão ampla da região (Quadro1).

Quadro1. "Tags" definidas pelo estudo

\begin{tabular}{|c|c|c|c|}
\hline \multirow{6}{*}{$\begin{array}{l}\text { Rio Doce } \\
\text { Bacia do rio } \\
\text { Doce } \\
\text { Rio Doce } \\
\text { catchment } \\
\text { Cuenca del } \\
\text { rio Doce }\end{array}$} & \multicolumn{3}{|c|}{$\begin{array}{c}\text { Xopotó / Piracicaba / Casca / Santo Antônio / Corrente Grande / Suaçuí Pequeno / Suaçuí Grande / } \\
\text { Manhuaçu / Matipó / Guandu / Pancas / São José }\end{array}$} \\
\hline & \multicolumn{3}{|c|}{$\begin{array}{l}\text { Minas Gerais / Mariana / Barra Longa / Santa Cruz do Escalvado / Rio Casca / Sem-peixe / São Pedro } \\
\text { dos Ferros / São Domingos do Prata / São José do Goiabal / Raul Soares / Dionísio / Córrego Novo / } \\
\text { Pingo D’água / Marliéria / Bom Jesus do Galho / Timóteo / Caratinga / Ipatinga / Santana do Paraíso / } \\
\text { Ipaba / Belo Oriente / Bugre / Iapu / Naque / Periquito / Sobrália / Fernandes Tourinho / Alpercata / } \\
\text { Governador Valadares / Tumiritinga / Galiléia / Conselheiro Pena / Resplendor / Itueta / Ponte Nova } \\
\text { / Aimorés }\end{array}$} \\
\hline & \multicolumn{3}{|c|}{ Espírito Santo / Baixo Guandu / Colatina / Aracruz / Marilândia / Linhares / Fundão } \\
\hline & $\begin{array}{c}\text { Hidrelétrica, PCH / UHE } \\
\text { Candonga, UHE Risoleta Neves, } \\
\text { UHE Baguari, UHE Aimorés, UHE } \\
\text { Mascarenhas }\end{array}$ & $\begin{array}{c}\text { Hydroelectric power plant: } \\
\text { Candonga, Risoleta Neves, } \\
\text { Baguari, Aimorés, } \\
\text { Mascarenhas }\end{array}$ & $\begin{array}{c}\text { Central Hidroeléctrica: Candonga, } \\
\text { Risoleta Neves, Baguari,Aimorés, } \\
\text { Mascarenhas }\end{array}$ \\
\hline & $\begin{array}{c}\text { Pesca / Pescaria / Pescado / Frutos } \\
\text { do Mar / Peixe }\end{array}$ & $\begin{array}{c}\text { Fishing / Fishery / Fish / } \\
\text { Seafood / }\end{array}$ & $\begin{array}{r}\text { Pesca/Pesce } \\
P e\end{array}$ \\
\hline & $\begin{array}{c}\text { Pesca artesanal / Pesca comercial / } \\
\text { Pesca Industrial / Pesca de } \\
\text { subsistência / Pesca esportiva/ } \\
\text { Pesca amadora / Pesque-pague / } \\
\text { Ornamental / Pesca continental / } \\
\text { Pesca marinha / Pesca estuarina / } \\
\text { Pesca extrativista / Pesca fluvial / } \\
\text { Pesca Ribeirinha }\end{array}$ & $\begin{array}{c}\text { Artisanal fishing / } \\
\text { Commercial fishing / } \\
\text { Industrial fishing / } \\
\text { Subsistence fishing / Sport } \\
\text { fishing / Fish pay pond/ } \\
\text { fishing pond / pay pond / } \\
\text { ornamental fish / } \\
\text { Continental fishing / } \\
\text { Marine fishing / Estuarine } \\
\text { Fishing (Fisheries) / } \\
\text { Extractive fishing / River } \\
\text { fishing / riverside fishing }\end{array}$ & $\begin{array}{l}\text { Pesca artesanal / Pesca comercial } \\
\text { / Pesca industrial / Pesca de } \\
\text { subsistencia / Pesca deportiva / } \\
\text { Coto de pesca / Pesca continental/ } \\
\text { Pesca marina / Pesca (pesquerías) } \\
\text { estearina / Pesca extractiva / } \\
\text { Pesca fluvial / Pesca fluvial }\end{array}$ \\
\hline
\end{tabular}


Citação (APA):Jankowsky, M., Carvalho, R. M. de, Gomes, V. A. do P., \& Freitas, R. R. de (2021). Peixes e Pesca na Bacia do Rio Doce, Uma Análise Bibliométrica. Brazilian Journal of Production Engineering, 6(8), Edição Especial "Pesca e Aquicultura: Gestão, Política e Inovação", 14-40.

Produção pesqueira / Produção de Pescado / Esforço de pesca /Perfil laboral pesca / Pescadores /

Trabalhadores da pesca / povos das águas / Comunidade pesqueira /

Ribeirinhos / Território Pesqueiro / Zona de pesca / área de pesca / Ordenamento (pesqueiro, pesca, pescarias)
Fishery production / Fish

Fisheries workers / Fishing

Estaleiro / Atracadouro / Píer / shipyard / berth / pier / Molhe / Marina / Estruturas de apoio náutico / Desembarque Pesqueiro / Descarga Pesqueira

Associações / Associação de Pescadores / Colônia / Comunidade/povos tradicional(is)

laboral pesca / Pescadores / Trabalhadores da pesca / povos das águas / Comunidade pesqueira /

Ribeirinhos / Território Pesqueiro / Zona de pesca / área de pesca

Comercialização Pescado / Peixe / Consumo de peixe / Consumo pescado

Embarcações / Barco(s) / Frota Pesqueira / canoa / Baitera / Lancha

Legislação da pesca / censo pesqueiro / monitoramento participativo / conflitos na pesca / manejo dos recursos naturais / Tamanho mínimo de captura / Ordenamento (pesqueiro, pesca, pescarias)/ Defeso (períodos) / Espécies protegidas

Artes de pesca / Artefatos de pesca / Aparelhos de pesca/Apetrecho de pesca / Rede/malha / anzol e linha (espinhel, linha de mão) / arrasto / dragas / armadilhas / mergulho / arpão / coleta de mão

Espécies de peixe / Espécies de crustáceos / Espécies de moluscos / Espécies de invertebrados / Nomes comuns / Tilápia/ Camarão /

Comunidades peixes / crustáceos / moluscos production / Catch/Catch per Unit effort/ CPUE / Fishing effort / Fishing profile / Fishermen / community / Artisanal fisherman, Fishing community / riverside / fishing territory / Fishing zone / fishing arealfishery space / Fisheries management marina / Structures of nautical support / Fishing Landing / Fish landing

Associations / Fishermen's Association / Colony/Union / Traditional community

Fishing profile / Fishermen / Fisheries workers / Fishing community / Artisanal fisherman, Fishing community / riverside / fishing territory / Fishing zone / fishing arealfishery space

Fish commercialization / commercialization $/$ Fish Sale / Fish consumption
Boat (s) / Fishing fleet / canoe / Speedboat/
Producción pesquera / Captural Captura por unidad de esfuerzo/CPUE/esfuerzo de pesca / Esfuerzo de pesca / Perfil de pesca / Pescadores / Trabajadores pesqueros / Comunidad de

Pescadores / Orilla, Comunidad de pescadores / comunidades

ribereñas / Territorio de pesca /

Zona de pesca / zona de pesca / Manejo pesquero

astillero / muelle / puerto pequeño / estructuras de apoyo náutico / Desembarco de pesca

Asociaciones / Asociación de Pescadores / Colonia / culturas/comunidades/los pueblos tradicionales

Perfil de pesca / Pescadores /

Trabajadores pesqueros /

Comunidad de Pescadores / Orilla,

Comunidad de pescadores / comunidades ribereñas / Territorio de pesca / Zona de pesca / zona de pesca

Comercialización de pescado/ Comercialización de pesca / Venta de pescado / Consumo de pescado

Barco (s) / Flota pesquera / canoa / Lancha rápida

Fisheries law (regulation) / Fishing census /

Legislación de pesca / censo

Participatory monitoring / pesquero / monitoreo participativo Fishing conflict /

Management of fishery resources / Minimum catch size / Fisheries management / Temporal closures / Protected species

Fishing gear / Fishing artifacts / Fishing tackle / Net/ fish net/mesh hook a line (longline, handline) / trawl / dredges / traps / diving / harpoon / hand collection

/ conflictos en la pesca / manejo de recursos naturales / Talla mínima de captura / Manejo pesquero /

Veda de pesca / Especies protegidas

Equipo de pesca / Artefactos de pesca / Aparejo de pescar / Red/malla / anzuelo y línea (espinel, línea de mano) / arrastre / dragas / trampa / buceo / arpón / colecta manual

Fish species / Crustacean species / Mollusk species / Invertebrate species / Common names / Tilapia / Shrimp / Fish communities (crustaceans / mollusks)
Especies de Peces / Especies de crustáceos / Especies de moluscos /

Especies de invertebrados /

Nombres comunes / Tilapia / (crustáceos / moluscos)
Camarón / Comunidad de peces 
Estrutura populacional (idades / tamanhos) / Unidade de estoque / estoque pesqueiro / banco de pescado / pesqueiro / Prospecção pesqueira / Estado de exploração / explotação / Determinação de idades / taxas de crescimento / Taxas de mortalidade / explotação / Abundância / biomassa / Captura por unidade de esforço (CPUE) / Esforço de pesca / Ciclos de vida

Aquicultura / Aquacultura / Aquaponia

Produção Aquícola / Cultivo aquícola / Consórcio / Produção consorciada / Policultivo

Viveiros / Viveiros escavados /
Tanque escavado / Tanque
concreto / Barragem / Barramento /
Tanque-rede

APP - Área de Preservação Permanente / Mata ciliar / Unidade (área) de conservação / etnoecologia / Habitats essenciais / Área de reprodução / reprodutiva Qualidade água / Mananciais / Afluentes / Tributários / Manguezais / Estuários / Plataforma continental / Talude Continental / Recifes / Cadeia / teia trófica / Produtividade primária

Fatores abióticos / Temperatura / Salinidade / Frentes oceanográficas / Descarga fluvial / Pluviosidade / Ressurgência / Massas d'água / Mudança climática

Perfil Socioeconômico / Sócio economia / PIB per capita /

Atividade econômica / Índice de

Gini /Índice de desenvolvimento humano / Coeficiente de

Williamson / População / Gênero / Raça/etnia / Idade

Populacional/composição etária / Demografia

Habitação / Distribuição espacial população / Ocupação do solo / Desenvolvimento / ocupação urbana / Gerenciamento costeiro integrado

$$
\text { Analfabetismo / }
$$

Educação/Escolaridade / Saúde / Saneamento básico / Criminalidade
Population structure (age / size) / Stock unit / fishing stock / fish bank / Fishing survey / Exploitation status

/Age determination / growth rate / Mortality rate / exploitation rate / Abundance / biomass /

Catch per unit effort (CPUE) / fishing effort Life history (cycles)

estructura de la población (edad / tallas) / Unidad de stock / stock de pesca / banco de peces /

Prospección pesquera / Estado de explotación / Determinación de edades / tasa de crecimiento / Tasa de mortalidad / Tasa de explotación / Abundancia / biomasa / Captura por unidad de esfuerzo (CPUE) / esfuerzo de pesca / Ciclo de vida

Aquaculture / Aquaponics

Acuicultura / Acuaponia

Aquaculture production / Aquaculture cultivation / Consortium / Consortium production / Polyculture

Producción acuícola / Cultivo de la acuicultura / Consorcio / Producción de consorcio / Policultivo

Hapas / Earth ponds/ nursery pond/ ponds / netcages / net tanks

Vivero / estanque / estanque de tierra / estanque de muro /

estanque recubierto/estanque de presa/ dique / Jaula flotante

Environmental Protection

Areas / Riparian forest /

Protected areas,

Conservation unities

(areas) / ethnoecology /

Essential habitats / Nursing areas

Water quality/ Springs / tributaries / Mangroves /

Estuaries / Continental

Shelf / Continental Slope /

Reefs / Food web / Primary productivity/

APP / Bosque de ribera / Unidades de Conservación / etnoecología/ Hábitats esenciales / Áreas de reproducción

Calidad del agua / Resortes / afluentes / Manglares / estuarios /

Plataforma continental / Talud Continental / Arrecifes / Red trófica / Producción primaria Abiotic factors /

Temperature/Salinity/ Factores abióticos/Temperatura/ Oceanographic fonts (or just fronts) / Fluvial discharge / Pluviosity / Upwelling / Water masses / Salinidad / Frentes oceánicos / Aporte fluvial / Pluviosidad / Resurgencia / Masas de Agua / Climate change

Socioeconomic profile / socioeconomics / Per capita GDP / economic activity /

Gini Index / Human

development index /

Williamson coefficient /

Population / gender Racel ethnicity / population age / Demography Cambio climático

Perfil socio-económico / socio economía / PIB per cápita / actividad económica / Índice de Gini / Índice de Desarrollo

Humano / Coeficiente de Williamson / población/ género / Raza/ etnia / edad de la población / demografía Housing / spatial distribution / Land use / Urban development (occupation)/Integrated coastal management Illiteracy / Education/schooling / Health / sanitation /
Alojamiento / Distribución

Espacial de la Población / Uso del suelo / Desarrollo (ocupación)

urbano / Manejo costero integrado

Educación/enseñanza / Salud/saneamiento / criminalidad / Analfabetismo / 


\begin{tabular}{|c|c|c|}
\hline $\begin{array}{c}\text { / Cultura / Recreação / Esporte / } \\
\text { Mortalidade infantil / Esperança de } \\
\text { vida ao nascer }\end{array}$ & $\begin{array}{l}\text { Criminal / Culture / } \\
\text { recreation / sport / Child } \\
\text { mortality/ Infant mortality / } \\
\text { Life expectancy at birth }\end{array}$ & $\begin{array}{c}\text { Cultura/recreación/deporte / } \\
\text { mortalidad infantil / esperanza de } \\
\text { vida al nacer }\end{array}$ \\
\hline $\begin{array}{l}\text { Metal pesado / Poluição / Esgoto / } \\
\text { Desmatamento / Assoreamento / } \\
\text { Espécies exóticas / Espécie exótica } \\
\text { invasora / Sobrepesca / Pesca } \\
\text { predatória / Pesca incidental / } \\
\text { Degradação ambiental / } \\
\text { Transformação da paisagem / } \\
\text { Desastre / Rompimento de } \\
\text { barragem / Atividades antrópicas / } \\
\text { Perda (destruição) de habitats }\end{array}$ & $\begin{array}{l}\text { Heavy metal / Pollution / } \\
\text { Sewage / Deforestation / } \\
\text { Siltation / Exotic species / } \\
\text { Invasive exotic species/ } \\
\text { Invasive Alien Species/ } \\
\text { Alien Fish / Overfishing / } \\
\text { Predatory fishing / by-catch } \\
\text { / Ambiental degradation / } \\
\text { Landscape transformation / } \\
\text { Disaster / dam collapse / } \\
\text { Human activities/Anthropic } \\
\text { activities / Habitat loss }\end{array}$ & $\begin{array}{l}\text { Metal pesado / Contaminación / } \\
\text { Alcantarillado / Deforestación / } \\
\text { Saltación / Especies exóticas / } \\
\text { especies exóticas invasoras / } \\
\text { Sobrepesca / Pesca depredadora / } \\
\text { Pesca fortuita / Degradación } \\
\text { ambiental / Transformación del } \\
\text { paisaje / ruptura de presa / } \\
\text { Actividades humanas Actividades } \\
\text { antrópica / pérdida de hábitat }\end{array}$ \\
\hline $\begin{array}{c}\text { APP - Área de Preservação } \\
\text { Permanente / Mata ciliar / Unidade } \\
\text { (área) de conservação / } \\
\text { etnoecologia / Qualidade água / } \\
\text { Mananciais / Afluentes / } \\
\text { Tributários }\end{array}$ & $\begin{array}{c}\text { Environmental Protection } \\
\text { Areas / Riparian forest / } \\
\text { Protected areas, } \\
\text { Conservation unities } \\
\text { (areas) / ethnoecology / } \\
\text { Water quality/ Springs / } \\
\text { tributaries }\end{array}$ & $\begin{array}{c}\text { APP / Bosque de ribera / Unidades } \\
\text { de Conservación / etnoecología / } \\
\text { Calidad del agua / Resortes / } \\
\text { afluentes }\end{array}$ \\
\hline
\end{tabular}

Fontes: Autores, 2020

Para busca das "tags" foram escolhidas bases de dados que possuíssem abrangência para uma gama de artigos de alta relevância, provenientes de periódicos de maior visibilidade na comunidade acadêmica (Quadro 2). O período de busca foi entre 1969 e junho de 2020. Como critério, foram selecionados somente os artigos que estavam disponíveis e liberados para download nos idiomas inglês, português ou espanhol.

Quadro 2. Bases de dados definidas e utilizadas.

\begin{tabular}{cc}
\hline Academic Resource Index-ResearchBib & Pubmed \\
Bioline International & RedalycAmeliCA \\
CAB Direct & SciELO - Scientific Electronic Library Online \\
Directory of Open Access Journals & Science Direct \\
EBM-Ovid & Scopus \\
Embase & Springer \\
Google Acadêmico & Sumários \\
Medline & WorldCat \\
Microsoft Academic Search & WOS - Web of Science \\
Online Journals Search Engine
\end{tabular}

Fontes: Autores, 2020.

Para avaliar as palavras do título, foi utilizada a ferramenta "nuvem de palavras", que é a representação de uma lista hierarquizada visualmente, com fins de classificação, em que a quantidade maior ou menor de aparições de determinado termo é dada proporcionalmente pelo tamanho da fonte (Lemos, 2016). Para a criação da nuvem de palavras, todos os títulos dos artigos, de todas as bases, foram utilizados em forma de texto e carregados na plataforma wordclouds ${ }^{\circledR}$ (https://www.wordclouds.com/). Seguindo a proposta de dar uma visão objetiva ao leitor, optou-se por retirar palavras redundantes para este estudo, como Rio Doce, Espírito Santo, Minas Gerais e Brasil, de forma a dar relevância às palavras mais utilizadas de forma específica aos estudos englobados neste portfólio. As palavras no singular e plural também foram agrupadas, ficando apenas a forma mais usada.

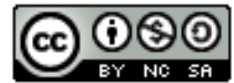


Para a análise qualitativa, foi empregada uma adaptação da metodologia PRISMA (Galvão, Pansani, \& Harrad, 2015), a qual consiste em um checklist com vinte e sete itens e um fluxograma de quatro etapas (Figura 2).

Figura 2. Etapas para seleção de artigos e avaliação bibliométrica qualitativa

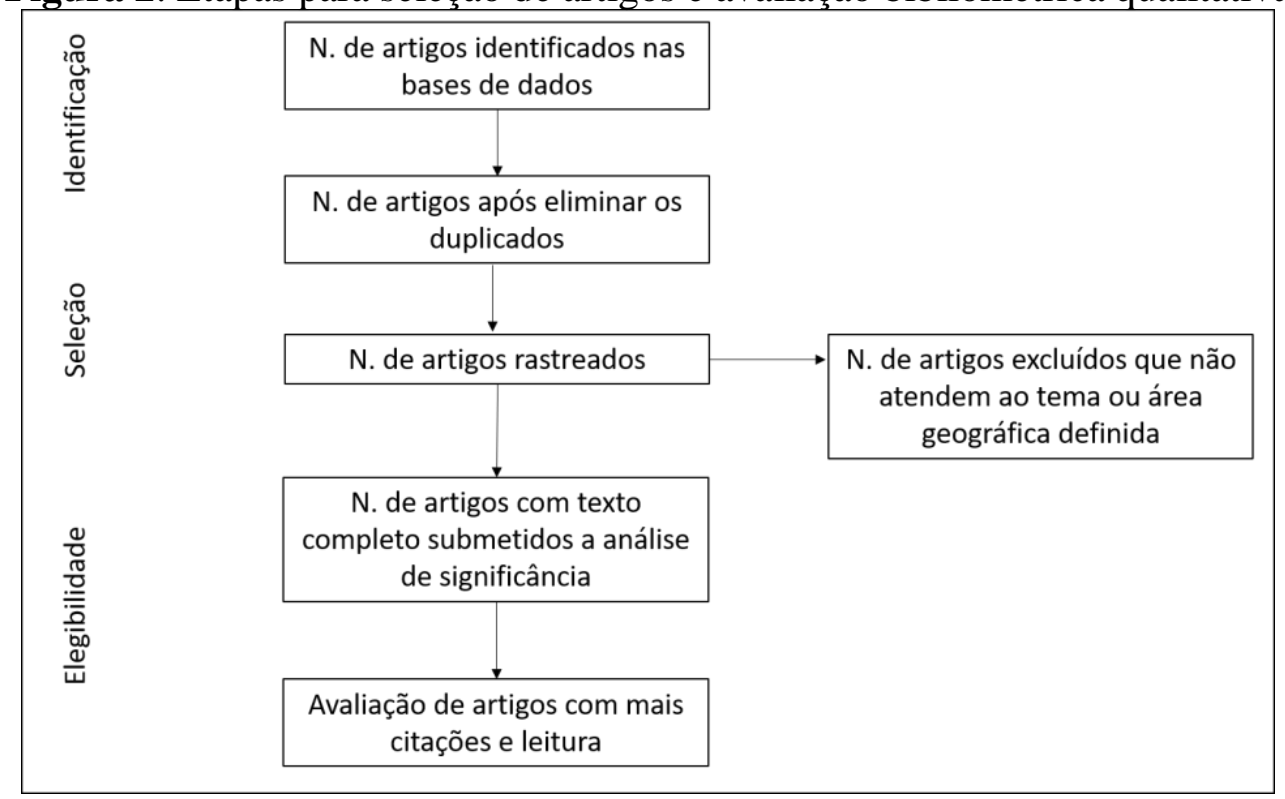

Fonte: Adaptado de Galvão, et al., 2015.

Conforme ilustrado na Figura 2, foi estabelecido o número amostral, ou seja, o número de artigos que deveria ser explorado em cada uma das bases. Considerando o nível de confiança, a população total (número de artigos nas bases) e a margem de erro, a amostra foi dimensionada por meio de cálculo amostral, estabelecido pela equação (Dupont \& Plummer, 1990):

$$
n=\frac{Z^{2} \cdot\left(\frac{x}{n}\right) \cdot\left[1-\left(\frac{x}{n}\right)\right] \cdot N}{(N-1) \cdot e^{2}+Z^{2} \cdot\left(\frac{x}{n}\right) \cdot\left[1-\left(\frac{x}{n}\right)\right]}
$$

Em que, $n$ representa o tamanho da amostra que se deseja estabelecer; $N$ é o tamanho da população; $e$ é o erro amostral; $\frac{x}{n}$ é a proporção estimada do item pesquisado na amostra (\%); e $Z$ é o valor da abscissa da curva normal associada ao nível de confiança (Barbetta, 2007).

Portanto, levando em conta as características da população, bem como o método de pesquisa selecionado, a amostragem foi do tipo probabilística, visto que contemplou uma população finita e acessível, e todos os seus elementos possuíram probabilidade de pertencer à amostra (Eckert, 2016). O erro amostral considerado aceitável foi de 5\%, como não se tem uma previsão estimada do tamanho da amostra utilizou-se o valor de $50 \%$ e o nível de confiança utilizado foi de $90 \%$.

\section{RESUltados E DiscuSSÃo}

\section{Análise quantitativa}

A busca por artigos retornou um total inicial de 720 artigos. Após a verificação da área de estudo e retirada dos artigos repetidos, trabalhou-se na análise quantitativa com 389 artigos (Figura 3). 
Figura 3. Análise temporal de artigos localizados em cada ano

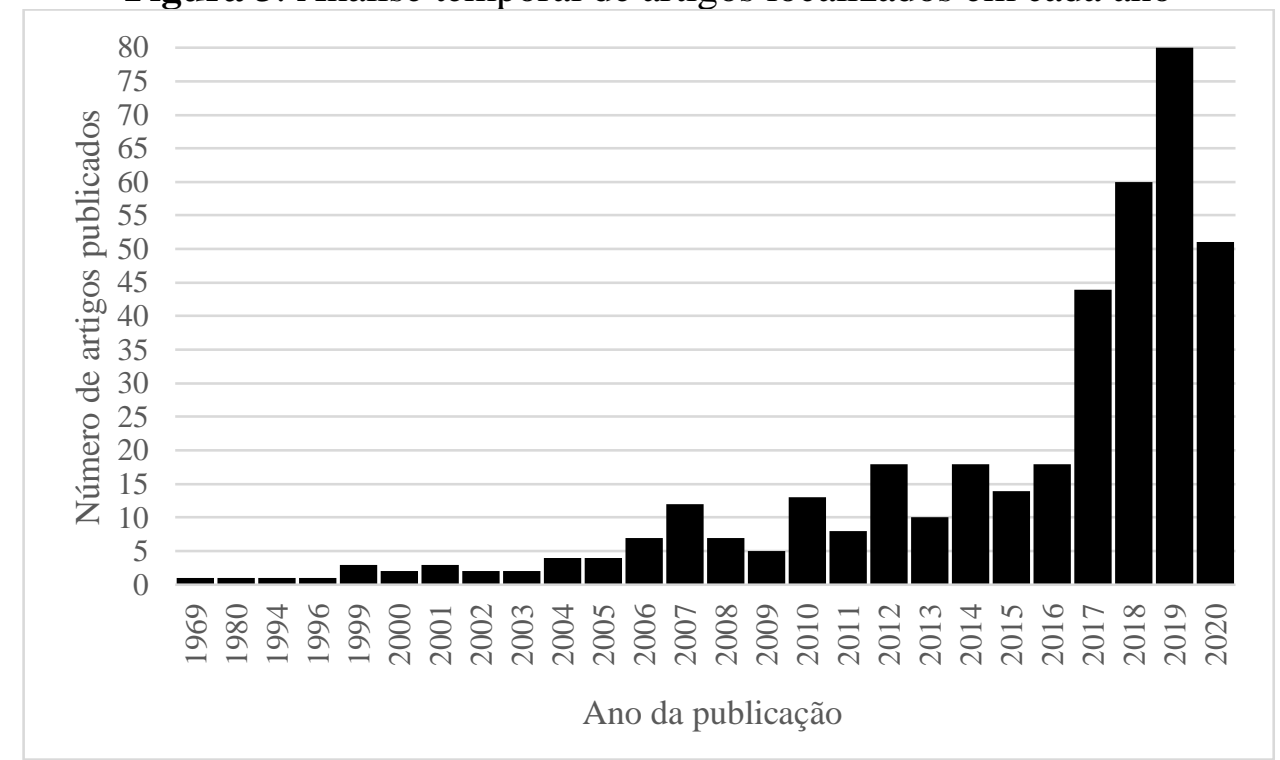

Fonte: Autores, 2020.

Nota-se que a partir de 1999, todos os anos houve publicação referente à Bacia Hidrográfica do Rio Doce. Destaque-se crescimento considerável no número de artigos publicados após 2015, ano em que ocorreu o rompimento da barragem de Fundão (Mariana/MG), atingindo no ano de 2019 um número de publicações superior a toda a década de 2000-2010. Conforme apontado anteriormente, os dados de 2020 consideram os artigos publicados até julho, devido o estabelecimento de uma data limite para coleta de dados.

Observa-se uma predominância de publicações por autores brasileiros, tanto no recorte até 2015, quanto após. Entretanto, nota-se que após 2015 a porcentagem de artigos publicados por pesquisadores brasileiros, em parceira com pesquisadores de outros países, aumentou (32 artigos com pesquisadores de 19 países). Diferente do período de 1969 a 2015, no qual houve apenas cinco artigos publicados em parceria com pesquisadores de outros quatro países (Tabela 1). Após 2015, também houve aumento de publicações de pesquisadores de outros países, mostrando maior interesse da comunidade científica internacional em desenvolver estudos na região.

Nota-se que as pesquisas no Estado de Minas Gerais nos dois períodos tiveram maior número de publicações. Entretanto, até 2015, os estudos ocorrem principalmente no médio Rio Doce, com grande destaque para pesquisas no PERD, e a partir de 2016 o foco passa para o alto Rio Doce, com destaque a área do rompimento da barragem do Fundão e seu entorno. A partir de 2016, observa-se pesquisas mais abrangentes, comparando com outras áreas, bem como no sistema marinho e ensaios de ecotoxicologia (Figura 4).

Tabela 1. País de origem dos autores dos trabalhos publicados.

\begin{tabular}{lcccc}
\hline País de origem dos autores & $\mathbf{1 9 6 9 - 2 0 1 5}$ & $\mathbf{\%}$ & $\mathbf{2 0 1 6 - 2 0}$ & $\mathbf{\%}$ \\
\hline Alemanha & 2 & 1,47 & - & - \\
Austrália & - & - & 2 & 0,79 \\
Brasil & 127 & 93,4 & 213 & 84,2 \\
Brasil e Alemanha & 2 & 1,47 & 3 & 1,19
\end{tabular}


Citação (APA):Jankowsky, M., Carvalho, R. M. de, Gomes, V. A. do P., \& Freitas, R. R. de (2021). Peixes e Pesca na Bacia do Rio Doce, Uma Análise Bibliométrica. Brazilian Journal of Production Engineering, 6(8), Edição Especial "Pesca e Aquicultura: Gestão, Política e Inovação", 14-40.

\begin{tabular}{lcccc}
\hline País de origem dos autores & $\mathbf{1 9 6 9 - 2 0 1 5}$ & $\mathbf{\%}$ & $\mathbf{2 0 1 6 - 2 0}$ & $\mathbf{\%}$ \\
\hline Brasil e Austrália & - & - & 3 & 1,19 \\
Brasil e Canadá & - & - & 2 & 0,79 \\
Brasil e Chile & - & - & 1 & 0,4 \\
Brasil e Espanha & 1 & 0,74 & 3 & 1,19 \\
Brasil e Estados Unidos & 1 & 0,74 & 7 & 2,77 \\
Brasil e França & 1 & 0,74 & 1 & 0,4 \\
Brasil e Holanda & - & - & 2 & 0,79 \\
Brasil e Portugal & - & - & 2 & 0,79 \\
Brasil e Reino Unido & - & - & 3 & 1,19 \\
Brasil, Austrália, Colômbia & - & - & 1 & 0,4 \\
Brasil, Canadá, Espanha, Alemanha & - & - & 1 & 0,4 \\
Brasil, Chile, Austrália & - & - & 1 & 0,4 \\
Brasil, Dinamarca, Reino Unido, África do Sul & - & - & 1 & 0,4 \\
Brasil, Estados Unidos, Canadá & - & - & 1 & 0,4 \\
Canadá & - & - & 1 & 0,4 \\
Dinamarca & - & - & 2 & 0,79 \\
Estados Unidos & - & - & 2 & 0,79 \\
Finlândia & - & - & 1 & 0,4 \\
México & 2 & 1,47 & - & - \\
\hline Total & $\mathbf{1 3 6}$ & - & $\mathbf{2 5 3}$ & - \\
\hline
\end{tabular}

Fonte: Autores, 2020.

Figura 4. Recorte espacial das pesquisas desenvolvidas e publicadas.

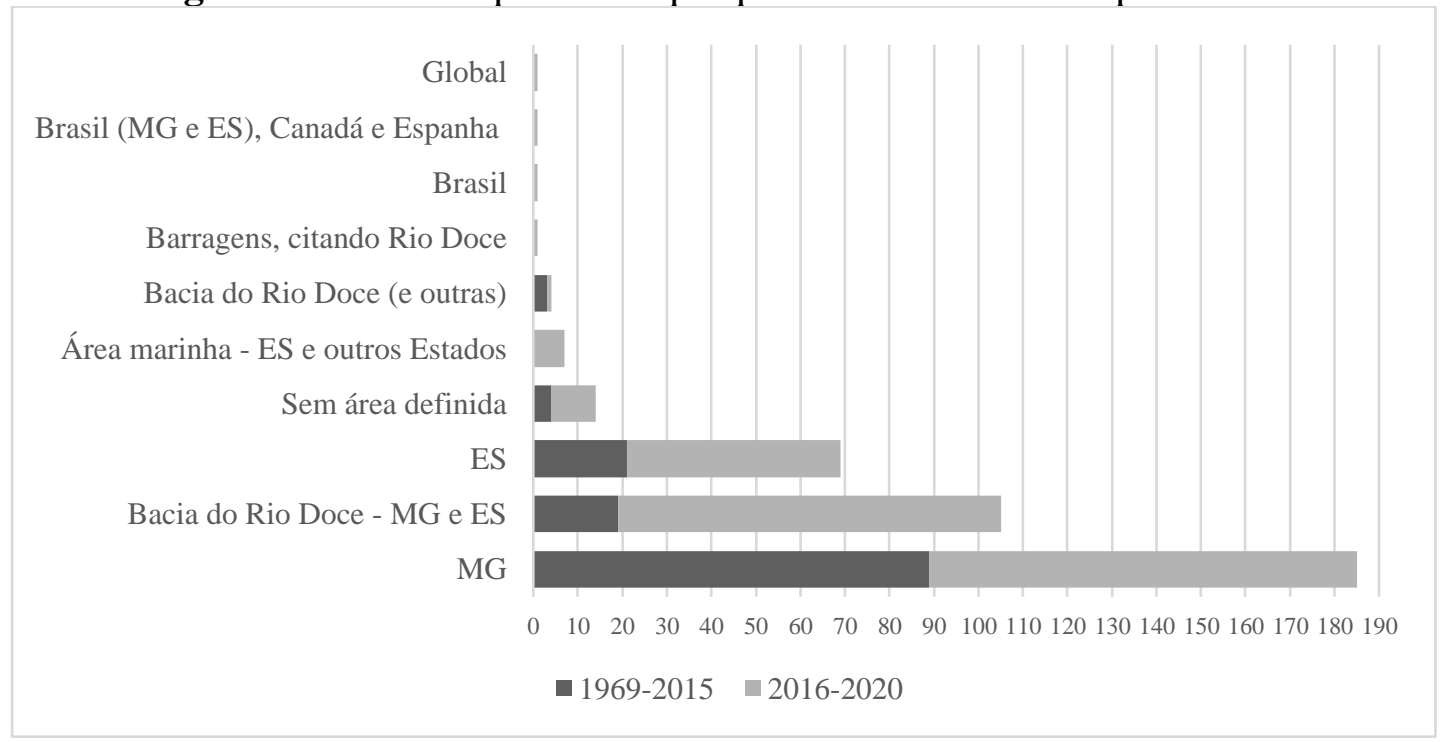

Fonte: Autores, 2020.

O idioma predominante nas publicações é o inglês, em qualquer um dos períodos analisados. Nenhuma publicação em espanhol foi localizada (Figura 5). 
Figura 5. Idioma utilizado nas publicações no período de 1969 a 2015, e de 2016 a 2020.

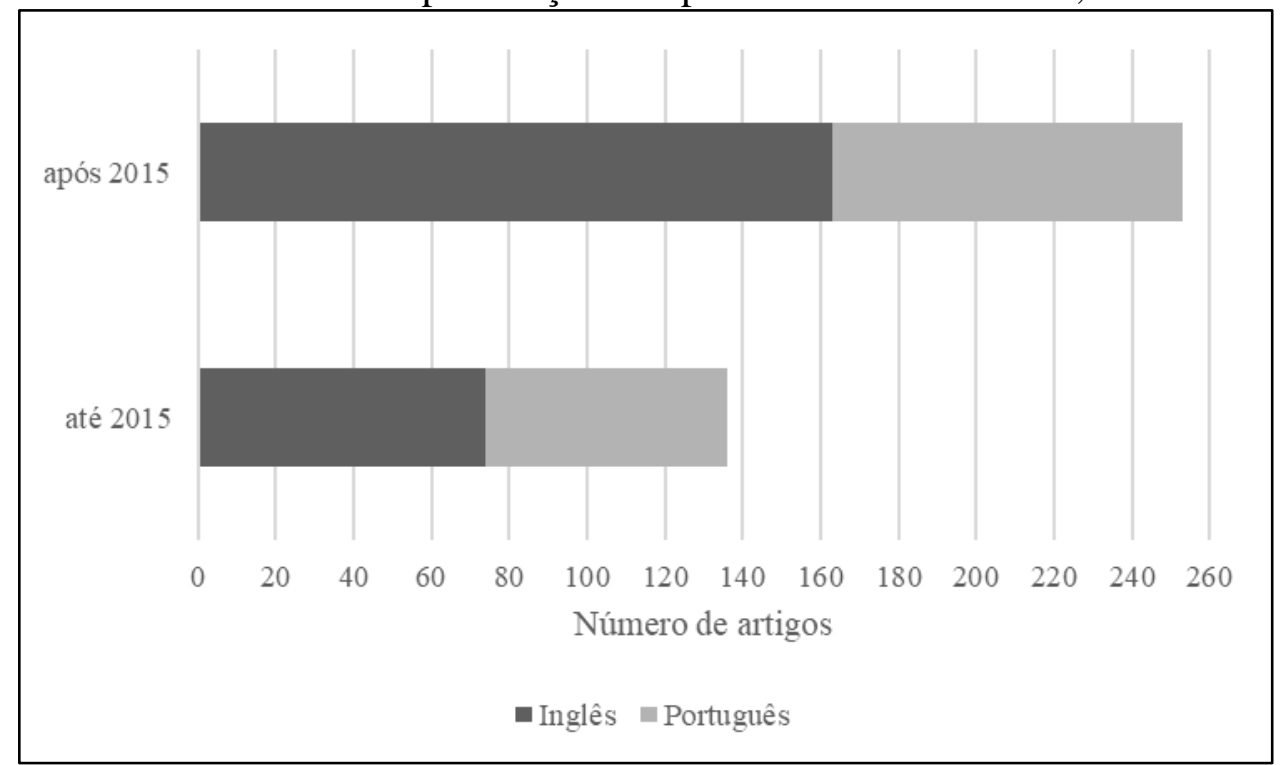

Fonte: Autores, 2020.

Em relação ao local de publicação, ao longo do tempo foram totalizados 230 diferentes periódicos científicos. Entre os títulos, novamente há diferença até 2015 e após esse período, indicando uma mudança no foco das pesquisas (Figuras 6 e 7). Os periódicos que publicaram apenas um artigo não constam nos gráficos, sendo 76 periódicos até 2015 e 127 entre 2016 e 2020.

Figura 6. Periódicos com ao menos duas publicações na região da Bacia do Rio Doce entre 1969 e 2015.

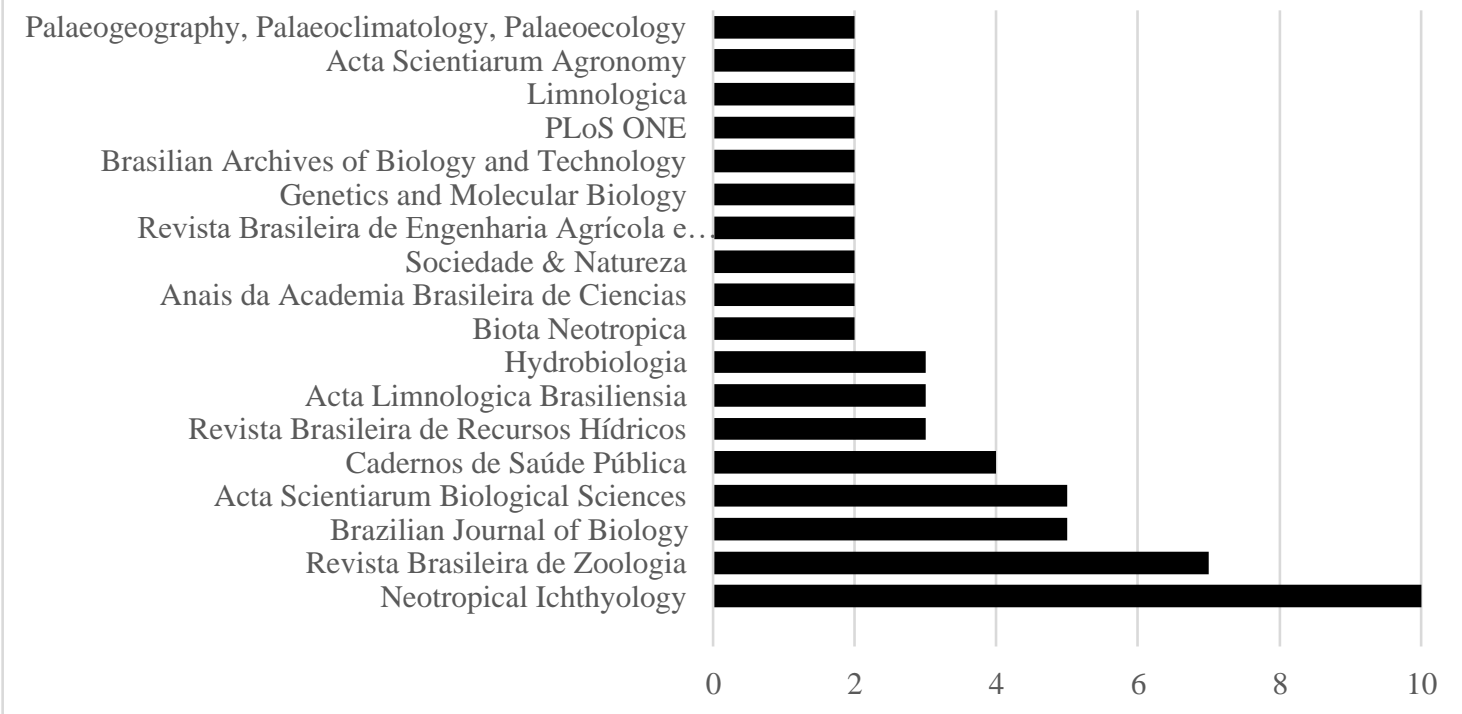

Fonte: Autores, 2020. 
Citação (APA):Jankowsky, M., Carvalho, R. M. de, Gomes, V. A. do P., \& Freitas, R. R. de (2021). Peixes e Pesca na Bacia do Rio Doce, Uma Análise Bibliométrica. Brazilian Journal of Production Engineering, 6(8), Edição Especial "Pesca e Aquicultura: Gestão, Política e Inovação", 14-40.

Figura 7. Periódicos com ao menos duas publicações na região da Bacia do Rio Doce entre 2016 e 2020.

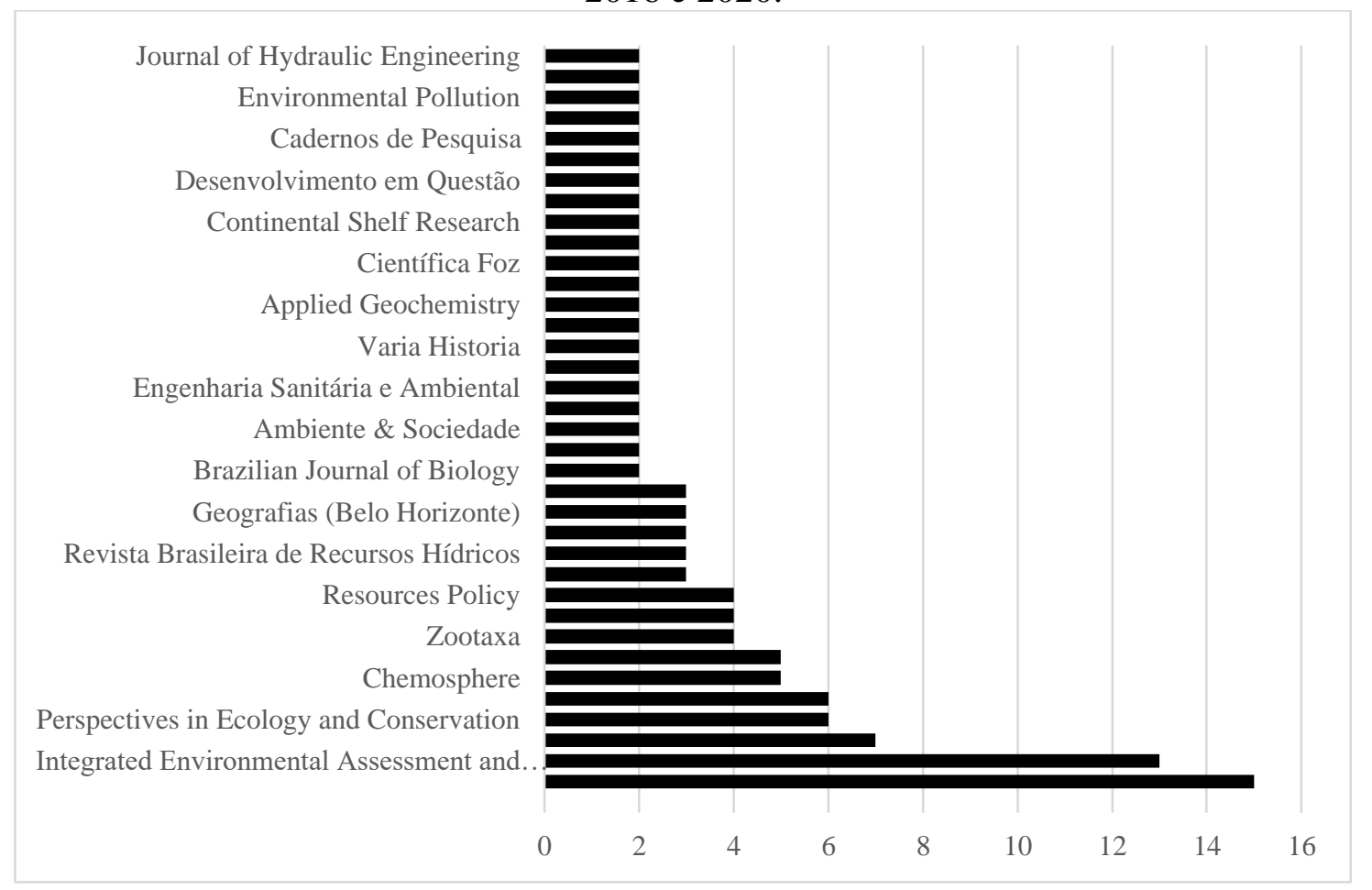

Fonte: Autores, 2020.

Finalizando a análise quantitativa, as palavras dos títulos também apresentaram grande diferença entre os dois recortes temporais (Figura 8). Nota-se a mudança entre "nova", "espécie", "lagos" e "peixe" para "barragem", "desastre", "rejeitos", "ambiental" e "mineração".

Figura 8. Resultados das wordclouds: à esquerda as palavras dos títulos observadas até 2015 e à direita entre 2016 e 2020.

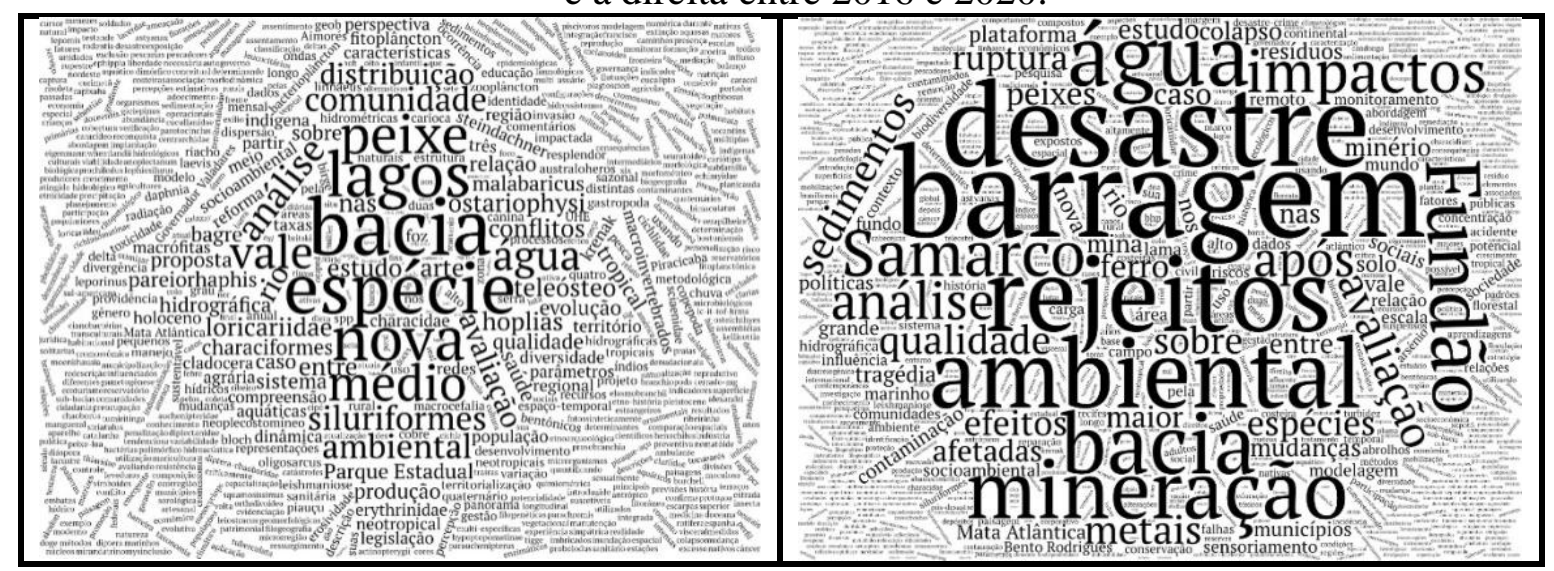

Fonte: Autores, 2020.

Observando os resultados das wordclouds e das principais revistas, nota-se que até 2015 a publicação da descoberta de novas espécies de peixes foi um dos principais focos, especialmente nas lagoas de Minas Gerais. Isto corrobora a classificação da região como hotspot para conservação (Marchese, 2015; Myers, et al., 2000), apontando para a descoberta 
Citação (APA):Jankowsky, M., Carvalho, R. M. de, Gomes, V. A. do P., \& Freitas, R. R. de (2021). Peixes e Pesca na Bacia do Rio Doce, Uma Análise Bibliométrica. Brazilian Journal of Production Engineering, 6(8), Edição Especial "Pesca e Aquicultura: Gestão, Política e Inovação", 14-40.

de novas espécies, e consequentemente aumento da riqueza local. Entretanto, após 2015 as pesquisas perdem o foco dos inventários de fauna e passam a analisar prioritariamente os impactos causados pelo desastre de Mariana.

\section{Análise qualitativa}

Após a visão geral das publicações na região, o cálculo de significância resultou na leitura de 278 artigos abrangendo diversas temáticas. Desse ponto em diante, considerando o objetivo central delineado, abordou-se exclusivamente os artigos referentes à ictiologia e atividade pesqueira. Dessa forma, foram analisados 54 artigos (Quadro 3).

Quadro 3. Artigos selecionados na análise qualitativa de ictiologia e atividade pesqueira.

\begin{tabular}{|c|c|}
\hline Título & Citação \\
\hline $\begin{array}{l}\text { A New Distinctively Colored Catfish of the Genus Pareiorhaphis (Siluriformes: } \\
\text { Loricariidae) from the Rio Piracicaba, Upper Rio Doce Basin, Brazil }\end{array}$ & (Pereira \& Britto, 2012) \\
\hline $\begin{array}{c}\text { A new species of Characidium (Characiformes: Crenuchidae) fromcoastalbasins in } \\
\text { the Atlantic Rainforest of eastern Brazil, with phylogenetic and phylogeographic } \\
\text { insights into the Characidium alipioi species group }\end{array}$ & (Malanski et al., 2019) \\
\hline $\begin{array}{l}\text { A new species of sexually dimorphic Pareiorhaphis Miranda Ribeiro, } 1918 \\
\text { (Siluriformes: Loricariidae) from the rio Doce basin, Brazil }\end{array}$ & $\begin{array}{l}\text { (Pereira, Vieira, \& Reis, } \\
\text { 2007) }\end{array}$ \\
\hline $\begin{array}{l}\text { A new species of the Neoplecostomine catfish Pareiorhaphis (Siluriformes: } \\
\text { Loricariidae) fromtheCoastalbasins of Espírito Santo, Eastern Brazil }\end{array}$ & $\begin{array}{l}\text { (Pereira, Pablo, \& Reis, } \\
\text { 2012) }\end{array}$ \\
\hline $\begin{array}{l}\text { A new species of TrichomycterusValenciennes } 1832 \text { (Trichomycteridae: Siluriformes) } \\
\text { fromthe Rio Doce drainage with remarkable similarities with Bullockia and a CT- } \\
\text { scansurvey }\end{array}$ & $\begin{array}{l}\text { (Reis, de Pinna, \& } \\
\text { Pessali, 2019) }\end{array}$ \\
\hline A Pesca Artesanal, Conflitos e Novas Configurações & $\begin{array}{l}\text { (Knox \& Trigueiro, } \\
\text { 2014) }\end{array}$ \\
\hline $\begin{array}{c}\text { An XX/XY sex chromosome system in a fishspecies, Hopliasmalabaricus, with a } \\
\text { polymorphic NOR-bearing X chromosome }\end{array}$ & (Born \& Bertollo, 2000) \\
\hline $\begin{array}{l}\text { Australoheros capixaba, a new species of Australoherosfromsouth-eastern Brazil } \\
\text { (Labroidei: Cichlidae: Cichlasomatinae) }\end{array}$ & (Ottoni, 2010) \\
\hline $\begin{array}{l}\text { Closely Related Syntopic Cytotypes of Astyanaxtaeniatus (Jenyns, 1842) } \\
\text { fromtheUpper Piranga River, Upper Doce Basin in Southeastern Brazil }\end{array}$ & (da Cunha et al., 2016) \\
\hline $\begin{array}{l}\text { Determining management units in southeastern Brazil: the case of Astyanax } \\
\text { bimaculatus (Linnaeus, 1758) (Teleostei: Ostariophysi: Characidae) }\end{array}$ & $\begin{array}{l}\text { (Paiva, Dergam, \& } \\
\text { Machado, 2006) }\end{array}$ \\
\hline $\begin{array}{l}\text { Effects of metal contaminationonliver in two fishspeciesfrom a highly impacted } \\
\text { neotropical river: A case study of the Fundão dam, Brazil }\end{array}$ & (Weber et al., 2020) \\
\hline $\begin{array}{l}\text { Evolutionary Divergence Among Oligosarcus spp. (Ostariophysi, Characidae) } \\
\text { fromthe São Francisco and Doce River Basins: Oligosarcus solitarius Menezes, } 1987 \\
\text { Shows the Highest Rates of Chromosomal Evolution in the Neotropical Region }\end{array}$ & $\begin{array}{l}\text { (Lucas Caetano de } \\
\text { Barros, Santos, Cioffi, \& } \\
\text { Dergam, 2015) }\end{array}$ \\
\hline $\begin{array}{l}\text { First Report of Austrodiplostomum compactum and Ithyoclinostomum dimorphum in } \\
\text { Trahira (Hopliasmalabaricus) fromtheMiddleCourse of the Rio Doce, Minas Gerais, } \\
\text { Brazil }\end{array}$ & (Belei et al., 2013) \\
\hline $\begin{array}{l}\text { Genotoxic, biochemical and bioconcentration effects of manganese on Oreochromis } \\
\text { niloticus (Cichlidae) }\end{array}$ & (Coppo et al., 2018) \\
\hline $\begin{array}{c}\text { Glanidium botocudo, a new species from the rio Doce and rio Mucuri, Minas Gerais, } \\
\text { Brazil (Siluriformes: Auchenipteridae) with comments on taxonomic position of } \\
\text { Glanidium bockmanni Sarmento-Soares \& Buckup }\end{array}$ & $\begin{array}{l}\text { (Sarmento-Soares \& } \\
\text { Martins-Pinheiro, 2013) }\end{array}$ \\
\hline $\begin{array}{l}\text { Habitats and littoral zone fish community structure of two natural lakes in southeast } \\
\text { Brazil }\end{array}$ & (Vono \& Barbosa, 2001) \\
\hline $\begin{array}{l}\text { Histological and molecular changes in gill and liver of fish (Astyanax lacustrisLütken, } \\
\text { 1875) exposed to water from the Doce basin after the rupture of a mining tailingsdam } \\
\text { in Mariana, MG, Brazil }\end{array}$ & (Macêdo et al., 2020) \\
\hline $\begin{array}{c}\text { How Are the Lakes? Environmental Perception by Fishermen and Alien Fish } \\
\text { Dispersal in Brazilian Tropical Lakes }\end{array}$ & $\begin{array}{l}\text { (F. P. Lima, Latini, De } \\
\text { Marco, \& Júnior, 2010) }\end{array}$ \\
\hline $\begin{array}{c}\text { Hydroacoustic assessment of fish and Chaoborus (Diptera-Chaoboridae) distribution } \\
\text { in three Neotropicallakes }\end{array}$ & $\begin{array}{l}\text { (Bezerra-Neto, } \\
\text { Brighenti, Mello, \& } \\
\text { Pinto-Coelho, 2012) }\end{array}$ \\
\hline
\end{tabular}


Citação (APA):Jankowsky, M., Carvalho, R. M. de, Gomes, V. A. do P., \& Freitas, R. R. de (2021). Peixes e Pesca na Bacia do Rio Doce, Uma Análise Bibliométrica. Brazilian Journal of Production Engineering, 6(8), Edição Especial "Pesca e Aquicultura: Gestão, Política e Inovação", 14-40.

\begin{tabular}{|c|c|}
\hline Título & Citação \\
\hline $\begin{array}{l}\text { Índice de Potencialidade Socioeconômica, Produtiva e Ambiental de Comunidades } \\
\text { Pesqueiras Situadas no Norte do Estado do Espírito Santo (IPSPA - Norte) }\end{array}$ & (Gomes \& Freitas, 2018) \\
\hline $\begin{array}{l}\text { Is the Doce River elutriateor its water toxictoAstyanax lacustres (Teleostei: } \\
\text { Characidae) threeyearsafterthe Samarco mining damcollapse? }\end{array}$ & (Passos et al., 2020) \\
\hline $\begin{array}{l}\text { Larval fish assemblages of the coastal area affected by the tailings of the collapsed } \\
\text { dam in southeast Brazil }\end{array}$ & $\begin{array}{l}\text { (Bonecker, Castro, } \\
\text { Costa, Bianchini, \& } \\
\text { Bonecker, 2019) }\end{array}$ \\
\hline $\begin{array}{l}\text { Length-weight relationship of } 21 \text { fish speciesfrom Rio Doce River basin, Minas } \\
\text { Gerais, Brazil }\end{array}$ & $\begin{array}{l}\text { (Salvador, Frederico, } \\
\text { Pessali, Vieira, \& } \\
\text { Freitas, 2018) }\end{array}$ \\
\hline $\begin{array}{l}\text { Loss of biodiversity in a conservation unit of the Brazilian Atlantic Forest: the effect } \\
\text { of introducing non-native fish species }\end{array}$ & $\begin{array}{l}\text { (Fragoso-Moura, Oporto, } \\
\text { Maia-Barbosa, \& } \\
\text { Barbosa, 2016) }\end{array}$ \\
\hline $\begin{array}{c}\text { Marine benthic communities affected by the Doce River (southwestern Atlantic): } \\
\text { Baseline before a mining disaster }\end{array}$ & $\begin{array}{l}\text { (Matthews-Cascon et al., } \\
\text { 2018) }\end{array}$ \\
\hline $\begin{array}{l}\text { Métodos de Coleta Utilizados na Captura de Tucunarés (Cichla spp.) para fins } \\
\text { Científicos }\end{array}$ & (Gomiero, 2010) \\
\hline $\begin{array}{l}\text { Neoplecostomus doceensis: a new loricariid species (Teleostei, Siluriformes) from the } \\
\text { rio Doce basin and comments about its putative origin }\end{array}$ & $\begin{array}{l}\text { (Roxo, Silva, Zawadzki, } \\
\quad \text { \& Oliveira, 2014) }\end{array}$ \\
\hline $\begin{array}{l}\text { New loricariid fishes from headwaters on Serra da Mantiqueira and Complexo do } \\
\text { Espinhaço, Minas Gerais State, Brazil (Teleostei: Siluriformes: Loricariidae) }\end{array}$ & $\begin{array}{l}\text { (J. C. Oliveira \& } \\
\text { Oyakawa, 2019) }\end{array}$ \\
\hline $\begin{array}{l}\text { Pareiorhaphis scutula, a new species of neoplecostomine catfish (Siluriformes: } \\
\text { Loricariidae) from the upper rio Doce basin, Southeastern Brazil }\end{array}$ & $\begin{array}{l}\text { (Pereira, Vieira, \& Reis, } \\
\text { 2010) }\end{array}$ \\
\hline $\begin{array}{c}\text { Parotocinclus planicauda, a new species of the sub family Hypoptopomatinae from } \\
\text { Southeastern Brazil (Ostariophysi: Loricariidae) }\end{array}$ & $\begin{array}{l}\text { (Garavello \& Britski, } \\
\text { 2003) }\end{array}$ \\
\hline $\begin{array}{l}\text { Pescarias Multi-Específicas na Região da Foz do Rio Doce, ES, Brasil: } \\
\text { Características, Problemas e Opções para um Futuro Sustentável }\end{array}$ & $\begin{array}{l}\text { (Pinheiro \& Joyeux, } \\
\text { 2007) }\end{array}$ \\
\hline $\begin{array}{c}\text { Phylogeography and RAPD-PCR variation in Hoplias malabaricus (Bloch, 1794) } \\
\text { (Pisces, Teleostei) in southeastern Brazil }\end{array}$ & $\begin{array}{l}\text { (Dergam, Paiva, } \\
\text { Schaeffer, Godinho, \& } \\
\text { Vieira, 2002) }\end{array}$ \\
\hline $\begin{array}{c}\text { Plagioscion squamosissimus (Sciaenidae) and Parachromis managuensis (Cichlidae): } \\
\text { A ThreattoNativeFishes of the Doce River in Minas Gerais, Brazil }\end{array}$ & $\begin{array}{l}\text { (Lucas C. Barros, Santos, } \\
\text { Zanuncio, \& Dergam, } \\
\text { 2012) }\end{array}$ \\
\hline $\begin{array}{l}\text { Potencialidade social e econômica da pesca e maricultura no Estado do Espírito Santo, } \\
\text { Brasil }\end{array}$ & $\begin{array}{l}\text { (Teixeira, Lima, } \\
\text { Boechat, Rodrigues, \& } \\
\text { Freitas, 2012) }\end{array}$ \\
\hline $\begin{array}{c}\text { Presence of the walking catfish Clarias gariepinus (Burchell) (Siluriformes, } \\
\text { Clariidae) in Minas Gerais state hydrographic basins, Brazil }\end{array}$ & $\begin{array}{l}\text { (Alves, Vono, \& Vieira, } \\
\text { 1999) }\end{array}$ \\
\hline $\begin{array}{l}\text { Redescription of Hisonotus notatus Eigenmann\&Eigenmann, } 1889 \text { (Loricariidae: } \\
\text { Hypoptopomatinae), thetypespecies of the genus, and description of a new species } \\
\text { from coastal drainages of southeastern Brazil }\end{array}$ & $\begin{array}{l}\text { (Martins \& Langeani, } \\
\text { 2016) }\end{array}$ \\
\hline $\begin{array}{l}\text { Redescription of Moenkhausia doceana (Steindachner, 1877) (Ostariophysi: } \\
\text { Characiformes): a characid from the Northeastern Mata Atlântica ecoregion, Brazil }\end{array}$ & $\begin{array}{l}\text { (Carvalho, Sarmento- } \\
\text { Soares, \& Martins- } \\
\text { Pinheiro, 2014) }\end{array}$ \\
\hline $\begin{array}{l}\text { Relação Preliminar das Espécies de Peixes (Pisces, Elasmobranchii, Actinopterygii) } \\
\text { Ameaçadas no Brasil }\end{array}$ & (Rosa \& Menezes, 1996) \\
\hline $\begin{array}{l}\text { Revision of the Neotropical trahiras of the Hoplias lacerdae species-group } \\
\text { (Ostariophysi: Characiformes: Erythrinidae) with descriptions of two } \\
\text { new species }\end{array}$ & $\begin{array}{l}\text { (Oyakawa \& Mattox, } \\
\text { 2009) }\end{array}$ \\
\hline Rio Doce Acoustic Surveys of Fish Biomass and Aquatic Habitat & $\begin{array}{l}\text { (Hobbs, Bigot, \& Smith, } \\
\text { 2020) }\end{array}$ \\
\hline $\begin{array}{l}\text { SeabedMorphology and Sedimentary Regimes defining Fishing Grounds along the } \\
\text { Eastern BrazilianShelf }\end{array}$ & $\begin{array}{l}\text { (Bourguignon et al., } \\
\text { 2018) }\end{array}$ \\
\hline $\begin{array}{l}\text { Simulatingshifts in taxonomic and functional-diversity of ray-finnedfishes: Probingthe } \\
\text { Mariana disaster }\end{array}$ & $\begin{array}{l}\text { (Trindade-Santos et al., } \\
\text { 2018) }\end{array}$ \\
\hline $\begin{array}{l}\text { Spatio-temporal segregation and size distribution of fish assemblages as relatedto non- } \\
\text { native species occurrence in the middle rio Doce Valley, MG, Brazil }\end{array}$ & $\begin{array}{l}\text { (Giacomini, Lima, } \\
\text { Latini, \& Espírito-Santo, } \\
\text { 2011) }\end{array}$ \\
\hline
\end{tabular}

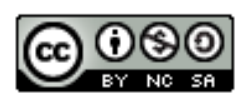

Esta obra está licenciada com uma Licença Creative Commons Atribuição-Não Comercial-Compartilha Igual 4.0 Internacional. Brazilian Journal of Production Engineering, São Mateus, Editora UFES/CEUNES/DETEC. 
Citação (APA):Jankowsky, M., Carvalho, R. M. de, Gomes, V. A. do P., \& Freitas, R. R. de (2021). Peixes e Pesca na Bacia do Rio Doce, Uma Análise Bibliométrica. Brazilian Journal of Production Engineering, 6(8), Edição Especial "Pesca e Aquicultura: Gestão, Política e Inovação", 14-40.

\begin{tabular}{|c|c|}
\hline Título & Citação \\
\hline $\begin{array}{l}\text { Systematics and biogeography of the genus Phalloceros Eigenmann, } 1907 \\
\text { (Cyprinodontiformes: Poeciliidae: Poeciliinae), with the description of twenty-one } \\
\text { new species }\end{array}$ & (Lucinda, 2008) \\
\hline $\begin{array}{c}\text { Taxonomy of Probolodus Eigenmann, } 1911 \text { (Characiformes:Characidae) with } \\
\text { description of two new species, and comments about the phylogenetic relationships } \\
\text { and biogeography of the genus }\end{array}$ & (Santos \& Castro, 2014) \\
\hline $\begin{array}{c}\text { The invertedtrophiccascade in tropical planktoncommunities: Impacts of exoticfish in } \\
\text { theMiddle Rio Doce lakedistrict, Minas Gerais, Brazil }\end{array}$ & $\begin{array}{l}\text { (Pinto-Coelho et al., } \\
\text { 2008) }\end{array}$ \\
\hline $\begin{array}{c}\text { The Unique Karyotype of Henochilus wheatlandii, a Critically Endangered Fish } \\
\text { Living in a Fast-Developing Region in Minas Gerais State, Brazil }\end{array}$ & (Silva et al., 2012) \\
\hline $\begin{array}{l}\text { Toxic and essential metals in Narcine brasiliensis (Elasmobranchii: Narcinidae): A } \\
\text { baseline ecotoxicologicalstudy in the Southeast Atlantic and preliminary maternal } \\
\text { transfer implications }\end{array}$ & (Lopes et al., 2019) \\
\hline $\begin{array}{l}\text { Traditional knowledge of Fishers versus an environmental disaster from mining waste } \\
\text { in Central Brazil }\end{array}$ & $\begin{array}{c}\text { (P. D. C. Oliveira, Di } \\
\text { Beneditto, Quaresma, } \\
\text { Bastos, \& Zappes, 2020) }\end{array}$ \\
\hline $\begin{array}{l}\text { Using ancient DNA to unravel taxonomic puzzles: the identity of Deuteron pedri } \\
\text { (Ostariophysi: Characidae) }\end{array}$ & $\begin{array}{l}\text { (Silva, Malabarba, \& } \\
\text { Malabarba, 2017) }\end{array}$ \\
\hline
\end{tabular}

Fonte: Autores, 2020.

Entre os principais temas abordados nos artigos selecionados, a descrição de novas espécies apresenta-se como o tema mais recorrente. Assim procurou-se apresentar os resultados em uma escala temporal os principais fatos ocorridos visando uma melhor leitura (Quadro 4).

Quadro 4. Síntese das novas espécies descritas na Bacia do Rio Doce.

\begin{tabular}{|c|c|c|c|}
\hline Ano & Espécie(s) descrita(s) & Local & Autores \\
\hline 2003 & Parotocinclus planicauda & Bacias do Rio Doce e São Francisco & Garavello \& Britski \\
\hline 2007 & Pareiorhaphis nasuta & alto Rio Doce & Pereira, Vieira \& Reis \\
\hline 2008 & Phalloceros elachistos & $\begin{array}{l}\text { drenagem do rio Doce e em pequenas bacias } \\
\text { costeiras do Estado do Espírito Santo }\end{array}$ & \multirow{3}{*}{ Lucinda } \\
\hline 2008 & Phalloceros harpagos & $\begin{array}{c}\text { bacia do rio Paraná-Paraguai e bacias costeiras } \\
\text { do Espírito Santo }\end{array}$ & \\
\hline 2008 & Phalloceros ocellatus & $\begin{array}{c}\text { drenagens costeiras dos Estados da Bahia e } \\
\text { Espírito Santo }\end{array}$ & \\
\hline 2009 & Hoplias intermedius & rio São Francisco, alto rio Paraná e rio Doce & \multirow{2}{*}{ Oyakawa \& Mattox } \\
\hline 2009 & H. brasiliensis & rios costeiros da drenagem Atlântica & \\
\hline 2010 & Australoheros capixaba & baixo Rio Doce & Ottoni \\
\hline 2010 & Pareiorhaphis scutula & médio Rio Doce & Pereira, Vieira \& Reis \\
\hline 2012 & Pareiorhaphis ruschii & Baixo Rio Doce & Pereira, Pablo e Reis \\
\hline 2012 & Pareiorhaphis proskynita & Alto Rio Doce & Pereira \& Britto \\
\hline 2013 & Glanidium botocudo & Alto Rio Doce & $\begin{array}{l}\text { (Sarmento-Soares \& } \\
\text { Martins-Pinheiro }\end{array}$ \\
\hline 2014 & Neoplecostomus doceensis & Alto Rio Doce & $\begin{array}{l}\text { Roxo, Silva, Zawadzki, \& } \\
\text { Oliveira }\end{array}$ \\
\hline 2014 & Moenkhausia doceana* & $\begin{array}{c}\text { lagoas do vale do rio Doce e ao longo das } \\
\text { bacias hidrográficas costeiras entre o Espírito } \\
\text { Santo e o sul da Bahia }\end{array}$ & $\begin{array}{l}\text { Carvalho, Sarmento-Soares } \\
\text { \& Martins-Pinheiro }\end{array}$ \\
\hline 2014 & Probolodus sazimai & $\begin{array}{c}\text { drenagens das bacias dos rios Itapemirim/ES e } \\
\text { Doce/ES e MG }\end{array}$ & Santos \& Castro \\
\hline 2016 & Hisono tusthayeri & $\begin{array}{l}\text { drenagens do rio Paraíba do Sul, Lagoa Feia, } \\
\text { rio Macaé e rios costeiros do estado do } \\
\text { Espírito Santo, como rio Itabapoana na bacia } \\
\text { do Rio Doce }\end{array}$ & Martins \& Langeani \\
\hline \multirow[b]{2}{*}{2019} & Harttia intermontana & cabeceiras da Bacia do Rio Doce & \multirow[b]{2}{*}{ Oliveira \& Oyakawa } \\
\hline & $\begin{array}{l}\text { Neoplecostomus } \\
\text { pirangaensis }\end{array}$ & Rio Piranga, bacia do Rio Doce & \\
\hline
\end{tabular}



Inovação", 14-40.

\begin{tabular}{|l|l|c|c|}
\hline 2019 & Characidium cricarense & Médio e baixo Rio Doce & $\begin{array}{c}\text { Malanski, Sarmento- } \\
\text { Soares, Silva-Malanski, } \\
\text { Lopes, Ingenito \& Buckup }\end{array}$ \\
\hline 2019 & $\begin{array}{l}\text { Trichomycterus } \\
\text { astromycterus }\end{array}$ & Alto é médio Rio Doce & Reis, Pinna \& Pessali \\
\hline
\end{tabular}

*redescrição

Fonte: Autores, 2020.

Aponta-se que além da descrição das espécies, alguns autores apresentam chaves de identificação, como ocorre com os gêneros: Parotocinclus (Garavello, \& Britski, 2003), Phalloceros (Lucinda, 2008) e Hoplias (Oyakawa \& Mattox, 2009). Dentre as espécies identificadas, algumas já foram classificadas quanto ao grau de ameaça, Hisono tusthayeri foi classifica como Pouco Preocupante (LC) (Martins \& Langeani, 2016) da mesma forma que Harttia intermontana (J. C. Oliveira \& Oyakawa, 2019). Já Neoplecostomus pirangaensis foi avaliada como Criticamente em Perigo (CR) (J. C. Oliveira \& Oyakawa, 2019).

Estudos de genética e citogenética também foram realizados na região do alto e médio Rio Doce. Alguns estudos apontam para diferenças genéticas dentro das populações que muitas vezes são perceptíveis na distribuição biogeográfica das espécies, como Astyanax bimaculatus, que tem variações genéticas e morfológicas associadas aos afluentes da Bacia do Rio Doce (Paiva et al., 2006), Astyanax taeniatus com diferenças entre dois citótipos que podem ter evoluído separadamente por especiação alopátrica (Da Cunha et al., 2016) e Hoplias malabaricus, com dois grupos populacionais, sendo um grupo nos rios e algumas lagoas e outro grupo presente apenas em lagoas (Dergam et al., 2002). Nesta última espécie, ainda se confirmou o heteromorfismo sexual XX/XY na população (citótipo $2 \mathrm{n}=42$ ) e acrescentou-se novo citótipo ao grupo (Born \& Bertollo, 2000). Oligosarcus argenteus e O. solitarius foram constatados com altos níveis de polimorfismo populacional na Bacia do Rio Doce (Lucas Caetano de Barros, et al., 2015). Houve ainda o detalhamento do cariótipo de Henochilus wheatlandii, uma espécie que já havia sido considerada como extinta, e hoje é tida como criticamente ameaçada. A espécie tem perfil citogenético similar a outras espécies da subfamília que é singular entre os neotropicais Bryconinae (Silva et al., 2012). Além disso, houve a melhoria da identificação da espécie Deuterodon pedri, a partir da análise genética, que permitiu sistematizar melhor os caracteres morfológicos da espécie (Silva et al., 2017).

Entre os estudos ecológicos há diversos tópicos abordados, como espécies ameaçdas, estrutura da comunidade de peixes, presença de parasitas entre outros. Para facilitar a leitura, os artigos são apresentados em ordem cronológica.

Em 1996, foi indicada uma primeira lista de espécies de água doce com risco de extinção, incluindo espécies presentes na Bacia do Rio Doce. 19 espécies foram tratadas como "em perigo", duas delas já possivelmente extintas, e todas de ambientes de água doce profundamente alterados pela atividade humana; e 11 espécies foram consideradas vulneráveis. Uma espécie, foi reconhecida como extinta (Rosa \& Menezes, 1996).

Em 2001, foi publicado estudo que avaliou a estrutura da comunidade de peixes em duas lagoas na região do médio Rio Doce (Vono \& Barbosa, 2001). Geophagus brasiliensis foi a espécie dominante. Concluiu-se que a diferença na abundância total de peixes em relação aos tipos de

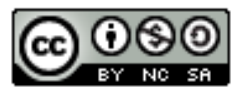


habitat, se deve, especialmente, a abundância de macrófitas, onde quanto maior a abundância de macrófitas, maior a complexidade da comunidade de peixes (Vono \& Barbosa, 2001).

Aponta-se ainda estudo sobre a melhor forma de coletar tucunarés para fins científicos. O autor indica o uso de tarrafas ou redes de arrasto nas margens para a coleta de juvenis e alevinos concomitantemente com a pesca de linha, usando iscas artificiais, para a captura de exemplares maiores (Gomiero, 2010).

Em 2012, foi publicado um estudo utilizando a técnica de hidroacústica para estudar a relação predador-presa em lagoas (Bezerra-Neto et al., 2012). Este estudo revelou o potencial de aplicação de abordagens acústicas para estudar o comportamento de peixes e organismos zooplanctônicos em sistemas aquáticos de água doce (Bezerra-Neto et al., 2012).

Em 2013, foi realizado o primeiro registro de parasitas metacercária em traíras provenientes do médio curso do rio Doce (Belei et al., 2013). Foram encontradas metacercárias de Austrodiplostomum compactum no humor aquoso dos olhos e metacercárias de Ithyoclinostomum dimorphum encistadas na cavidade peritoneal. Observou-se também a presença de ovos nestes parasitos (Belei et al., 2013).

Em 2018, foi publicado um estudo estabelecendo os coeficientes de alometria de 21 espécies da Bacia do Rio Doce: Hypomasticus mormyrops, H. thayeri, Brycon dulcis, B. opalinus, Henochilus wheatlandii, Astyanax lacustres, A. scabripinnis, Knodus moenkhausii, Olisarcus acutirostris, O. argenteus, O. solitarius, Prochilodus costatus, P. vimboides, Glanidium botocudo, Delturus carinotus, Euryochus thysanos, Hypostomus luetkeni, Pareiorhaphis scutula, Pareiorhaphis vetula, Lophiosilurus alexandri, Australoheros ipatinguensis (Salvador et al., 2018).

Neste mesmo ano, foi publicado estudo avaliando a diversidade da macrofauna bentônica marinha sob a influência do rio Doce, ainda que as coletas tenham se dado em 2011 e 2011. A análise de agrupamento mostrou a formação de três grupos faunísticos: 1) formado por áreas próximas a foz do rio Doce, que se caracterizavam por um substrato de lama e areia fina, e maior presença de Capitellidae e Magelonidae (Polychaeta); 2) áreas onde as características granulométricas foram areia média sem a presença de biodetrito, onde Spionidae e Syllidae (Polychaeta) foram mais representativas; 3) áreas distantes da foz do rio Doce, que se caracterizavam pela presença de biodetrito, habitats mesofóticos e concentrações médias a altas de $\mathrm{CaCO}_{3}$. No inverno, a análise apresentou um padrão muito semelhante ao apresentado no verão (Matthews-Cascon et al., 2018).

Outra temática bastante abordada refere-se a presença e impacto de espécies exóticas. $\mathrm{O}$ primeiro trabalho selecionado relatando a presença de espécies exóticas é de 1999 (Alves et al., 1999), relatando a presença de bagre africano, Clarias gariepinus, nas Bacias Hidrográficas do Rio Doce, Paraná e São Francisco. O estudo aponta os riscos relacionados a presença da espécie. Posteriormente, em 2012, ainda com foco no registro de espécies exóticas, foi relatada a presença de Plagioscion squamosissimus (pescada-amazônica) e Parachromis managuensis (jaguar) nos municípios de Caratinga e Rio Doce (Lucas C. Barros et al., 2012). Neste estudo os autores ainda relatam a presença de espécies exóticas já registradas anteriormente: Cichla

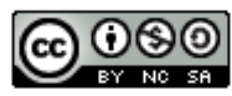


monoculus (tucunaré), Oreochromis niloticus (tilápia), Hoplosternum littorale (tamoatá, caborja), e Poecilia reticulata (barrigudinho, guarú).

Além do registro de espécies exóticas, há estudos sobre o impacto destas. Em 2008, foi avaliado o efeito da introdução em lagoas do médio Rio Doce, avaliando além da assembleia de peixes, fatores físico-químicos e o fitoplâncton (Pinto-Coelho et al., 2008). O estudo mostrou que a introdução dos predadores Pygocentrus nattereri (piranha-vermelha) e Cichla ocellaris (tucunaré) não só causou uma forte redução no número de espécies nativas, como também mudanças nos níveis tróficos inferiores. Pouco depois das introduções, a maioria das lagoas começou a mostrar alterações na comunidade fitoplanctônica, tais como o aparecimento da dominância de Cyanophyceae. A comunidade zooplanctônica perdeu diversas espécies e, em alguns casos, houve o desaparecimento de todas as espécies de cladóceroslimnéticos. Por outro lado, predadores invertebrados (família Chaoboridae) floresceram nos lagos com maiores densidades de espécies exóticas de peixes (Pinto-Coelho et al., 2008).

Buscando avaliar outras correlações quanto ao impacto das espécies exóticas, em 2011, foram avaliadas 11 lagoas no médio Rio Doce em três diferentes condições: sem espécies exóticas, com espécies exóticas e piscívoras, com espécies exóticas não piscívoras (Giacomini et al., 2011). O estudo mostrou que a composição das assembleias de peixes nativos está significativamente relacionada à presença e ao tipo de espécie exótica: piscívora ou não. Onde há espécies exóticas piscívoras, as espécies nativas de menor porte tendem a estar menos concentradas, ou seja, tais têm maior susceptibilidade à predação pelos invasores. Além disso, notou-se que a variabilidade temporal na composição foi significativamente maior em lagos com não nativos (Giacomini et al., 2011).

Outra abordagem utilizada em um estudo realizado na lagoa Carioca, comparou a composição da ictiofauna (2006 e 2010) e dados de 1983. Conclui-se que houve o desaparecimento de sete espécies nativas, registradas em estudos anteriores. Cyphocharax gilbert (saguiru) e Moenkhausia doceana (lambari) não foram capturados após a detecção de Cichla kelberi (tucunaré). Entre as espécies nativas, houve baixa representatividade nas amostragens da maioria das espécies remanescentes, evidenciando o alto impacto da invasão de peixes exóticos na comunidade estudada (Fragoso-Moura et al., 2016).

Avaliando os impactos causados pelo rompimento da barragem do Fundão, em novembro de 2015, tem-se estudos sobre a assembleia de peixe no qual foram feitas simulações para avaliar a diversidade $\beta$ na Bacia do Rio Doce, comparando com os dados das bacias hidrográficas adjacentes (Trindade-Santos et al., 2018). Tanto para análise de diversidade taxonômica e funcional foram usados quatro cenários de análise com a remoção de espécies da Bacia do Doce de $25,50,75$ e $100 \%$. Os resultados apontam que qualquer que seja o nível de extinção, as perdas de diversidade funcional ultrapassariam a diversidade taxonômica (Trindade-Santos et al., 2018). Ainda, analisando apenas a biomassa de peixes pelágicos, os resultados do Programa de Bioaucústica, iniciado em abril de 2017, indicaram níveis similares da biomassa pelágica entre os pontos controle e impactados. A análise temporal preliminar do conjunto de dados sobre a biomassa indicou níveis estáveis ou crescentes deste parâmetro nos locais impactados pelos rejeitos, no Rio Doce (Hobbs et al., 2020). Estes dois estudos trazem resultados sobre a 
ictiofauna através de métodos que dispensam a captura de indivíduos, mas também acabam por apontar para uma lacuna sobre a diversidade taxonômica e funcional com base em trabalhos de identificação de espécies, uma vez que a biomassa retornou à condição pré rompimento da barragem, mas não a diversidade no ecossistema.

Entretanto, inúmeros estudos avaliando a contaminação resultante do rompimento da barragem vem apontado elevada contaminação das espécies estudadas ; (Coppo et al., 2018; Bonecker et al., 2019; Lopes et al., 2019; Macêdo et al., 2020; Passos et al., 2020; Weber et al., 2020). Também, tendo como base os valores da concentração de manganês presentes na água do rio Doce logo após o rompimento, observou-se um experimento com tilápia, Oreochromis niloticus, para verificar os efeitos do metal sobre a espécie (Coppo et al., 2018). Ainda que a tilápia seja uma espécie exótica, é a espécie aquícola de maior importância na região (IBGE, 2020). Para análise, os animais foram expostos a um gradiente de concentrações, sendo a solução mais concentrada próxima aos valores encontrados no rio Doce - 0,0;0,2; 1,5 e 2,9 $\mathrm{mg} / \mathrm{L}$ manganês por $96 \mathrm{~h}$. Essas exposições causaram a formação significativa de micronúcleos eritrocitários nos organismos expostos a mais alta concentração, bem como um aumento significativo no índice de danos ao DNA de eritrócitos de organismos expostos a 1,5 mg/L e tratamentos de 2,9 mg/L. A atividade da enzima glutationa $\mathrm{S}$-transferase também mostrou um aumento significativo no fígado dos organismos expostos a $2,9 \mathrm{mg} / \mathrm{L}$. No entanto, a atividade da catalase aumentou significativamente nas brânquias dos animais expostos a todas as concentrações de manganês testadas (Coppo et al., 2018).

Já na região costeira, entre fevereiro e abril de 2016 (entre três e cinco meses após o rompimento), foi realizado estudo para identificar as larvas de peixes presente em amostras coletadas ao longo da área marinha que foi afetada por lama poluída, proveniente do rompimento da Barragem de Fundão, e verificou-se os danos causados às larvas de peixes (Bonecker et al., 2019). Um total de 4.182 larvas de peixes foram identificados compreendendo 52 famílias e 75 espécies. As assembleias eram dominadas por famílias demersais (32), seguidas de famílias epipelágica (15) e mesopelágica (5). A família Carangidae foi representada em maior número de espécies, seguido por Sciaenidae, Gobiidae e Monacanthidae. Clupeidae, Engraulidae, Chloroscombrus chrysurus, Gerreidae, Eucinostomus spp., Labridae e Gobiidae foram os táxons mais frequentes no período de coleta. Um total de $10 \%$ das larvas de peixes que foram identificadas em frente à foz do rio Doce, em janeiro/abril, apresentavam sedimentos avermelhados aderidos aos seus corpos. Os tratos digestivos de algumas larvas de Chloroscombrus chrysurus e Monacanthus ciliatus, coletadas em abril, estavam danificados. A análise, que foi realizada com ambas espécies, mostrou que eles tinham maiores concentrações de metais pesados do que os resultados obtidos de larvas sem danos, coletados ao mesmo tempo, e as larvas obtidas antes do acidente. Esse resultado confirma a existência de impacto da pluma de lama em assembleias de larvas de peixes da região costeira e reforçam a necessidade de continuar monitorando os impactos do rompimento na região costeira (Bonecker et al., 2019).

Ainda na região costeira, analisou a presença de metais tóxicos e atóxicos em Narcine brasiliensis, utilizando-a como espécie bioindicadora. Características como alta abundância relativa, longevidade e área de vida restrita, bem como hábitos bentônicos foram consideradas

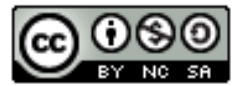


pertinentes para tanto (Lopes et al., 2019)(Lopes et al., 2019). Vários metais tóxicos foram observados em todos os órgãos de $N$. brasiliensis, com ênfase especial em níveis extremamente altos de arsênio. Estatisticamente, notou-se correlação significativa entre manganês um elemento essencial, e prata, um elemento tóxico em embriões de classe de tamanho dois e tecidos maternos. Observou-se também a presença de metais tóxicos no órgão elétrico e gônadas que podem levar a uma possível alteração na reprodução e bioeletrogênese (Lopes et al., 2019).

Em traíra, Hoplias intermedius, e cascudo, Hypostomus affinis avaliou-se o efeito da contaminação por metais pesados realizando coletas a montante (controle) e a jusante do rompimento da barragem (Weber et al., 2020), três anos após o rompimento da barragem. Estas espécies são amplamente distribuídas na Bacia do Rio Doce e são consideradas ecologicamente resistentes às mudanças ambientais, capazes de viver em rios altamente impactados. Os resultados demonstram que as duas espécies analisadas apresentaram grandes danos. Em comparação com o controle, a concentração de manganês foi estatisticamente mais alta na água, enquanto o chumbo, o níquel e o arsênio foram estatisticamente maiores no sedimento e o ferro não tinha nenhuma diferença significativa entre os sites. No local controle, peixes de ambas as espécies apresentavam tecido hepático com arquitetura normal. No local impactado, alterações hepáticas, como vacuolização citoplasmática e necrose foram frequentes encontrado em ambas as espécies. Em relação ao índice histopatológico, valores mais elevados foram encontrados em ambas as espécies na área impactada. As reações positivas do anticorpo para o citocromo P4501A e metalotioneína foram estatisticamente maiores no local impactado para ambas as espécies. Os biomarcadores de estresse oxidativo, superóxido dismutase e catalase foram estatisticamente maiores em $H$. intermedius do local impactado, mas apenas catalase foi estatisticamente maior em $H$. affinis no local impactado. No fígado nota-se a indução de proteínas e enzimas associadas com contaminação por metal no local impactado. Além disso, na área controle também foram capturadas outras espécies de peixes, ou seja, dois characiformes (Astyanax bimaculatus e Oligosarcus argenteus), um perciforme (Geophagus brasiliensis) e dois siluriformes (Hypostomus auroguttatus e Rhamdia quelen). No entanto, o local impactado pelo derramamento foi capturado apenas $H$. intermedius e H. affinis. Isso indica que espécies mais sensíveis às modificações ambientais podem não resistir este ambiente aquático altamente contaminado (Weber et al., 2020).

Ainda em 2018, foram realizados ensaios com lambari Astyanax lacustris avaliando os efeitos da água e do elutriato sobre a espécie. Em um dos ensaios foram analisadas as mudanças no fígado e brânquias, que foram expostos por sete dias à água amostrada formando um gradiente com quatro grupos - P1 a montante do rompimento da barragem, P2 $22 \mathrm{~km}$ a jusante do rompimento, P3 à 48 km, e P4 a 70 km da jusante da ruptura da barragem (Macêdo et al., 2020). Todos os grupos de tratamento mostraram alterações histológicas nas brânquias e no fígado, com a maior quantidade dessas alterações encontrada no grupo P2, local mais próximo ao rompimento da barragem. O estudo revelou que a água da Bacia do Rio Doce pode promover alterações histológicas no fígado e brânquias de peixes, bem como modulação da perturbação do equilíbrio iônico, respostas celulares ao estresse e vias de desintoxicação celular (Macêdo et al., 2020). 
Em um segundo ensaio foram avaliado os efeitos tóxicos do elutriato e da água, coletados na região estuarina do rio Doce (Passos et al., 2020). Para tanto realizou um bioensaio por meio da exposição subcrônica à água do rio Doce e três concentrações de elutriato (10, 50 e 100\%). Os pesquisadores concluíram que o elutriato não foi prejudicial para os peixes avaliados, uma vez que agentes complexantes presentes no sedimento, como goethita e hematita, podem ter desencadeado a quelação dos metais. Nesse cenário, o elutriato pode ter atuado como agente protetor dos organismos submetidos, ao contrário das águas do rio Doce, em que os contaminantes se mostraram perigosos para a biota aquática (Passos et al., 2020).

Importante destacar que as pesquisas sobre a atividade pesqueira ocorrem em grande parte na região litorânea. Na comunidade de Povoação, no município de Linhares, descreveu-se as atividades de pesca e do conhecimento tradicional das capturas, sendo relatadas 27 artes de pesca, tanto de pesca comercial, recreacional e de subsistência, registrando 63 espécies de peixes referentes a 27 famílias e 10 ordens nas capturas. Os pescadores demonstram conhecimento detalhado sobre o comportamento, a reprodução, a alimentação e a migração dos peixes, exemplificado nas estratégias de pesca. Os autores apontam para a necessidade da adoção de métodos de manejo pautados no conhecimento local (Pinheiro \& Joyeux, 2007). Na faixa litorânea, foi estabelecida a relação entre a batimetria e a composição do substrato com as artes de pesca usadas (Bourguignon et al., 2018). Nota-se que a área de regime de transporte de sedimentos é associada a um leito de sedimentação fino/lamacento terrígeno, que controla a morfologia local e favorece a progradação costeira e frontal do delta, e a região da pesca de camarão onde ocorre intensa pesca de arrasto, bem como pescarias com redes de emalhar visando pescada amarela e corvina. O regime de acomodação ou área de baixo influxo de sedimentos é caracterizado por carbonato sedimentação associada a solos duros e leitos de rodolitos que facilitam a extensa colonização bentônica por algas coralinas crustosas, e está principalmente associada à pesca com linha, espinhel e caça submarina (Bourguignon et al., 2018).

Ainda na região litorânea, avaliou-se as mudanças no território da pesca artesanal e seus efeitos nas comunidades de pescadores. Contextualizando a realidade da pesca artesanal são apresentadas grandes mudanças, como adensamento populacional, turismo, aumento do esforço pesqueiro, presença de atividades industriais e portuárias, associadas a escassez de pescado. Aponta-se assim um baixo investimento monetário na pesca artesanal como fruto de uma concepção equivocada de desenvolvimento, na qual uma atividade familiar não é vista como capaz de gerar riquezas e melhorias. A percepção sobre as atividades de maior impacto na pesca mudam de acordo com a região do Estado. Na parte central, o porto e a dragagem são apontados, ao norte, as atividades de sísmica. Em todas as regiões, o conflito com as traineiras. Frente a esses entraves, alguns pescadores questionam a efetividade dos períodos de defeso, e narram seu descumprimento. Relatam ainda problemas burocráticos com normas conflitantes das diferentes agências fiscalizadoras, reguladoras e credenciadoras marítimas e ambientais. Por fim, os autores destacam o desenvolvimento transformado em ideologia hegemônica, mascarando as principais atividades impactadoras (Knox \& Trigueiro, 2014).

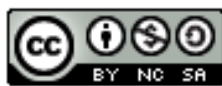


Também, a falta de investimento nas atividades de pequena escala é corroborada pela avaliação dos aspectos econômicos e sociais da pesca e da maricultura no litoral do Espírito Santo por Teixeira et al., (2012). Os resultados mostram que especialmente a região Norte variou do ponto de partida precário (Linhares), a pouco favorável (Aracruz), ainda que os municípios de Guarapari e Itapemirim tem como ponto de partida em condições muito favoráveis e se destacam por possuir o maior número de embarcações no Estado. Frente aos resultados, apontase a necessidade do poder público (municípios e Estado), estabelecer políticas de incentivo permanente a maricultura e pesca, como linhas de crédito compatíveis com o perfil do pescador tradicional. Além disso, indicam a necessidade de acompanhamento das atividades para o sucesso delas. Por fim, indicam a necessidade de parceria entre o setor e o poder público para fortalecer o associativismo, identificando gargalos e propondo soluções para o desenvolvimento da atividade e a redução das desigualdades sociais.

As baixas condições sociais entre a comunidade pesqueira também foram apontadas em Conceição da Barra, São Mateus e Linhares, na avaliação do potencial socioeconômico, produtivo e ambiental da pesca (Gomes \& Freitas, 2018). Nesse estudo é apresentada a criação de índice de potencialidade, no qual Conceição da Barra foi o município com melhor índice, pelo melhor resultado no subíndice produtivo, que teve maior peso.

Aponta-se que os impactos indicadores de Knox \& Trigueiro (2014) foram avaliados antes do rompimento da barragem de Fundão. Após, nos municípios de Conceição da Barra, Regência e Barra do Riacho, foi realizado estudo que teve como objetivo compreender a percepção dos pescadores artesanais da região litorânea sobre a viabilidade da pesca. De acordo com os entrevistados, todo o ecossistema costeiro no norte do Espírito Santo foi afetado pela suspensão da pesca, contaminação e diminuição das capturas e degradação da Bacia do Rio Doce. Para a maioria dos pescadores, a "Samarco" foi a responsável pelo desastre e não teve ação eficaz para evitar maior contaminação, após o rompimento. Ralatam também que, ao longo dos anos, os resíduos do rompimento da barragem ainda serão continuamente carreados para o oceano, devido às chuvas, e que o oceano será "limpo" em alguns anos. Essa dispersão de "lama tóxica" descrita pelos entrevistados realmente condiz com o apresentado na literatura.

Independentemente da suspensão da pesca após o desastre, a pesca ilegal ainda ocorre. Os entrevistados justificaram essas ações, afirmando que a compensação financeira oferecida pela Samarco é inferior a renda obtida anteriormente. Sobre o futuro da pesca artesanal na região após o desastre, pescadores acreditam que a atividade acabará eventualmente, pois ainda há o problema da contaminação e as populações de peixes diminuíram. Além disso, houve redução no valor comercial da captura local, dada a contaminação. Aponta-se que os pescadores ainda não entendem a extensão real do desastre. Destaca-se que a empresa ofereceu poucas soluções para os problemas sociais e ambientais e que esta deve promover maneiras de alcançar o desenvolvimento cultural socioeconômico em que afetou as comunidades (P. D. C. Oliveira et al., 2020).

Por fim, a pesca no Estado de Minas Gerais, nas comunidades de Baixa Verde e Cava Grande, municípios de Dionísio e Marliéria, analisou-se o impacto da presença de espécies exóticas sob o olhar das comunidades afetadas. Os resultados mostram que as comunidades apontam 
mudanças nos sistemas naturais, mas relacionam mais com os regimes climáticos. As espécies invasoras são percebidas pela maioria dos entrevistados, mas pouco mais da metade pode explicar o que é uma espécie invasora. Além disso, a introdução é vista como uma medida conservacionista. O pouco conhecimento sobre espécies invasoras é destacado, sendo recomendado uma etapa de educação científica sobre o tema nos planos de manejo e gestão da região (F. P. Lima et al., 2010).

\section{CONCLUSÃo}

É notória a mudança de foco entre as pesquisas realizadas na Bacia do Rio Doce, uma vez que o rompimento da barragem de Fundão impõe uma nova agenda de pesquisa com vistas a avaliar o impacto gerado e melhores formas de mitigação e reparação. Nota-se um esforço da comunidade acadêmica na geração de conhecimento no menor tempo possível, expresso pelo aumento no número de publicações, bem como nas parcerias com grupos de pesquisas de fora do Brasil. Destaca-se ainda que o risco de contaminação da atividade de mineração não foi foco das pesquisas até 2015 .

Em relação a ictiofauna, evidencia-se o grande número de espécies descobertas no alto e médio rio Doce, bem como o impacto da introdução de espécies exóticas, em contraste com escassas pesquisas sobre a atividade pesqueira. De forma inversa, na região costeira, há pesquisas com as atividades pesqueiras, em contraponto com o baixo número de pesquisas sobre espécies ou diversidade.

Entretanto, seja com o enfoque sobre a atividade pesqueira ou sobre a ictiofauna, há consenso sobre a gravidade do dano causado pelo rompimento da barragem do Fundão. Apenas a pesquisa relativa à biomassa de organismos pelágicos apontou um resultado próximo ao ambiental não impactado, ainda que esse resultado nada revele sobre a diversidade taxonômica e funcional ou sobre a contaminação destes organismos. $\mathrm{O}$ dano à diversidade funcional é destacado, visto que os estudos relativos à contaminação mostram efeitos à ictiofauna em toda a extensão da Bacia do Rio Doce, bem como na zona litorânea.

Por fim, o impacto sobre a pesca é apontado em diversas vertentes: contaminação, proibição de pesca, desvalorização do pescado, dificuldade de reparação e reconhecimento do dano causado. Esses fatores são agravados pelas condições apresentadas em outros estudos aqui apresentados, como as baixas condições sociais, falta de infraestrutura, o baixo investimento na pesca artesanal em detrimento de grandes obras.

\section{AgRADECIMENTOS}

Projeto de Monitoramento e Caracterização Socioeconômica da Atividade Pesqueira no Rio Doce e no Litoral do Espírito Santo. PG 16 - Programa de Retomada das Atividades Aquícolas e Pesqueiras. Fundação Renova. Acordo de Cooperação (Instituto de Pesca via FUNDEPAG e UFES via Fundação Espírito-santense de Tecnologia).

\section{REFERÊNCIAS BIBLIOGRÁFICAS}

Alves, C. B. M., Vono, V., \& Vieira, F. (1999). Presence of the walking catfish Clarias gariepinus (Burchell) (Siluriformes, Clariidae) in Minas Gerais state hydrographie basins,

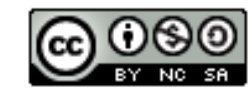


Citação (APA):Jankowsky, M., Carvalho, R. M. de, Gomes, V. A. do P., \& Freitas, R. R. de (2021). Peixes e Pesca na Bacia do Rio Doce, Uma Análise Bibliométrica. Brazilian Journal of Production Engineering, 6(8), Edição Especial "Pesca e Aquicultura: Gestão, Política e Inovação", 14-40.

Brazil. Revista Brasileira de Zoologia, 16(1), 259-263.

Barbetta, P. A. (2007). Estatística Aplicada Às Ciências Sociais (7 $7^{\text {a }}$ Edição.). Florianópolis: UFSC.

Barros, Lucas C., Santos, U., Zanuncio, J. C., \& Dergam, J. A. (2012). Plagioscion squamosissimus (Sciaenidae) and Parachromis managuensis (Cichlidae): A threat to native fishes of the Doce River in Minas Gerais, Brazil. PLoS ONE, 7(6), 1-5.

de Barros, Lucas Caetano, Santos, U., Cioffi, M. D. B., \& Dergam, J. A. (2015). Evolutionary divergence among Oligosarcus spp. (Ostariophysi, Characidae) from the São Francisco and Doce River Basins: Oligosarcus solitarius Menezes, 1987 shows the highest rates of chromosomal evolution in the Neotropical Region. Zebrafish, 12(1), 102-110.

Bartolini, M., Bottani, E., \& Eric, H. (2019). Green warehousing: Systematic literature review and bibliometric analysis. Journal of Cleaner Production, 226, 242-258.

Belei, F., Ferreira, S. R., Perin, L. M., Braga, F. R., Sampaio, W. M. S., Araújo, J. V. de, Dergam, J. A., et al. (2013). First report of austrodiplostomum compactum and ithyoclinostomum dimorphum in trahira (Hoplias malabaricus) from the middle course of the Rio Doce, Minas Gerais, Brazil. Arquivos do Instituto Biológico, 80(2), 249-252.

Bezerra-Neto, J. F., Brighenti, L. S., Mello, N. A. S. T. de, \& Pinto-Coelho, R. M. (2012). Hydroacoustic assessment of fish and Chaoborus (Diptera-Chaoboridae) distribution in three Neotropical lakes. Acta Limnologica Brasiliensia, 24(1), 18-28.

Bonecker, A. C. T., Castro, M. S. d., Costa, P. G., Bianchini, A., \& Bonecker, S. L. C. (2019). Larval fish assemblages of the coastal area affected by the tailings of the collapsed dam in southeast Brazil. Regional Studies in Marine Science, 32, 100848. Elsevier B.V. Retrieved from https://doi.org/10.1016/j.rsma.2019.100848

Born, G. G., \& Bertollo, L. A. C. (2000). An XX/XY sex chromosome system in a fish species, Hoplias malabaricus, with a polymorphic NOR-bearing $\mathrm{X}$ chromosome. Chromosome Research, 8, 111-118.

Bourguignon, S. N., Bastos, A. C., Quaresma, V. S., Vieira, F. V., Pinheiro, H., Amado-Filho, G. M., De Moura, R. L., et al. (2018). Seabed morphology and sedimentary regimes defining fishing grounds along the eastern Brazilian shelf. Geosciences (Switzerland), 8(3). Retrieved from https://www.mdpi.com/2076-3263/8/3/91

Brasil, M. da A. e P. (2020). SisRGP. Retrieved July 17, 2020, from http://sistemasweb.agricultura.gov.br/pages/SISRGP.html

Brasil, M. da J. (2020). FUNAI Geoprocessamento. Retrieved July 16, 2020, from http://www.funai.gov.br/index.php/shape

Brasil, M. do M. A. (2020). ICMBio Cadastro de Unidades de Conservação. Retrieved July 15, 2020, from https://www.mma.gov.br/areas-protegidas/cadastro-nacional-de-ucs/dadosgeorreferenciados.html

Carvalho, F. R., Sarmento-Soares, L. M., \& Martins-Pinheiro, R. F. (2014). Redescription of Moenkhausia doceana (Steindachner, 1877) (Ostariophysi: Characiformes): A characid from the Northeastern Mata Atlântica ecoregion, Brazil. Neotropical Ichthyology, 12(2), 377-388.

Coppo, G. C., Passos, L. S., Lopes, T. O. M., Pereira, T. M., Merçon, J., Cabral, D. S., Barbosa, B. V., et al. (2018). Genotoxic, biochemical and bioconcentration effects of manganese on Oreochromis niloticus (Cichlidae). Ecotoxicology, 27(8), 1150-1160. Springer US. Retrieved from http://dx.doi.org/10.1007/s10646-018-1970-0

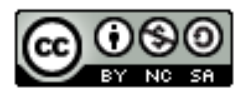


Citação (APA):Jankowsky, M., Carvalho, R. M. de, Gomes, V. A. do P., \& Freitas, R. R. de (2021). Peixes e Pesca na Bacia do Rio Doce, Uma Análise Bibliométrica. Brazilian Journal of Production Engineering, 6(8), Edição Especial "Pesca e Aquicultura: Gestão, Política e Inovação", 14-40.

Da Cunha, M. S., Reis, V. J. C., \& Dergam, J. A. (2016). Closely Related Syntopic Cytotypes of Astyanax taeniatus (Jenyns, 1842) from the Upper Piranga River, Upper Doce Basin in Southeastern Brazil. Zebrafish, 13(2), 112-117.

Dergam, J. A., Paiva, S. R., Schaeffer, C. E., Godinho, A. L., \& Vieira, F. (2002). Phylogeography and RAPD-PCR variation in Hoplias malabaricus (Bloch, 1794) (Pisces, Teleostei) in southeastern Brazil. Genetics and Molecular Biology, 25(4), 379-387.

Dupont, W. D., \& Plummer, W. D. (1990). Power and sample size calculations. Controlled Clinical Trials, 11(2), 116-128. Retrieved from https://linkinghub.elsevier.com/retrieve/pii/019724569090005M

Eckert, A. (2016). Antecedentes da intenção de recompra dos consumidores no contexto de compras On-Line. Universidade de Caxias do Sul.

Fragoso-Moura, E. N., Oporto, L. T., Maia-Barbosa, P. M., \& Barbosa, F. A. R. (2016). Loss of biodiversity in a conservation unit of the Brazilian Atlantic Forest: the effect of introducing non-native fish species. Brazilian Journal of Biology, 76(1), 18-27.

Galvão, T. F., Pansani, T. de S. A., \& Harrad, D. (2015). Principais itens para relatar Revisões sistemáticas e Meta-análises: A recomendação PRISMA. Epidemiologia e Serviços de Saúde, 24(2), 335-342.

Garavello, J. C., \& Britski, H. A. (2003). Parotocinclus planicauda, a new species of the subfamily Hypoptopomatinae from southeastern Brazil (Ostariophysi: Loricariidae). Brazilian journal of biology - Revista brasleira de biologia, 63(2), 253-260.

Giacomini, H. C., Lima, D. P., Latini, A. O., \& Espírito-Santo, H. M. V. (2011). Spatiotemporal segregation and size distribution of fish assemblages as related to non-native species occurrence in the middle rio doce valley, MG, Brazil. Neotropical Ichthyology, 9(1), 135-146.

Gomes, V. A. do P., \& Freitas, R. R. de. (2018). Índice de potencialidade socioeconômica, produtiva e ambiental de comunidades pesqueiras situadas no norte do Estado do Espírito Santo (IPSPA - Norte). Revista Produção Online, 18(1), 36-62.

Gomiero, L. M. (2010). Métodos de Coleta Utilizados na Captura de Tucunarés (Cichla spp.) PARA FINS CIENTÍFICOS. Revista Brasileira de Engenharia de Pesca, 5(1), 1-13.

Hobbs, D., Bigot, M., \& Smith, R. (2020). Rio Doce Acoustic Surveys of Fish Biomass and Aquatic Habitat. Integrated Environmental Assessment and Management, 00(00), 1-7.

IBGE, I. B. de G. e E. (2020). IBGE Cidades. IBGE Cidades. Retrieved July 17, 2020, from https://cidades.ibge.gov.br/

Knox, W., \& Trigueiro, A. (2014). A pesca artesanal, conflitos e novas configurações REDDRevista Espaço de Diálogo e Desconexão, Araraquara, v.8, n.1 e 2. 2014 A Pesca Artesanal, Conflitos e Novas Configurações. REDD - Revista Espaço de Diálogo e Desconexão, 8(1).

Lemos, L. M. P. (2016). Nuvem de tags como ferramenta de análise de conteúdo: uma experiência com as cenas estendidas da telenovela Passione na internet. Lumina, 10(1), 1-18.

Lima, A. T., Bastos, F. A., Junior, F. J. T., Neto, R. R., Gomes, H. I., \& Barroso, G. F. (2021). Doce River Large-Scale Environmental Catastrophe: Decision and Policy-Making Outcomes. Environment and development: Challenges, policies and practices (pp. 133-173). Cham: Springer International Publishing. Retrieved from http://link.springer.com/10.1007/978-3-03055416-3_5

Lima, A. T., Bastos, F. A., Teubner, F. J., Neto, R. R., Cooper, A., \& Barroso, G. F. (2020). Strengths and Weaknesses of a Hybrid Post-disaster Management Approach: the Doce River

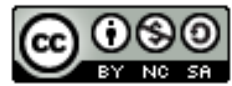


(Brazil) Mine-Tailing Dam Burst. Environmental Management, 65(6), 711-724. Retrieved from http://link.springer.com/10.1007/s00267-020-01279-4

Lima, F. P., Latini, A. O., De Marco, P., \& Júnior, P. D. M. (2010). How are the lakes? Environmental perception by fishermen and alien fish dispersal in Brazilian tropical lakes. Interciencia, 35(2), 84-91.

Lopes, C. A., Araujo, N. L. F., Rocha, L., Monteiro, F., Rocha, R. C. C., Saint'Pierre, T. D., Lutfi, D. S., et al. (2019). Toxic and essential metals in Narcine brasiliensis (Elasmobranchii: Narcinidae): A baseline ecotoxicological study in the Southeast Atlantic and preliminary maternal transfer implications. Marine Pollution Bulletin, 149(April), 110606. Elsevier. Retrieved from https://doi.org/10.1016/j.marpolbul.2019.110606

Losekann, C. (2017). "It Was No Accident!" the Place of Emotions in the Mobilization of People Affected By the Collapse of Samarco'S Tailings Dam in Brazil. Vibrant: Virtual Brazilian Anthropology, 14(2), 1-25.

Lucinda, P. H. F. (2008). Systematics and biogeography of the genus Phalloceros Eigenmann, 1907 (Cyprinodontiformes: Poeciliidae: Poeciliinae), with the description of twenty-one new species. Neotropical Ichthyology, 6(2), 113-158.

Macêdo, A. K. S., Santos, K. P. E. dos, Brighenti, L. S., Windmöller, C. C., Barbosa, F. A. R., Ribeiro, R. I. M. de A., Santos, H. B. dos, et al. (2020). Histological and molecular changes in gill and liver of fish (Astyanax lacustris Lütken, 1875) exposed to water from the Doce basin after the rupture of a mining tailings dam in Mariana, MG, Brazil. Science of the Total Environment, 735.

Malanski, E., Sarmento-Soares, L. M., Silva-Malanski, A. C. G., Lopes, M. M., Ingenito, L. F. da S., \& Buckup, P. A. (2019). A new species of Characidium (Characiformes: Crenuchidae) from coastal basins in the Atlantic Rainforest of eastern Brazil, with phylogenetic and phylogeographic insights into the Characidium alipioi species group. Neotropical Ichthyology, 17(2), 1-13.

Marchese, C. (2015). Biodiversity hotspots: A shortcut for a more complicated concept. Global Ecology and Conservation, 3, 297-309. Elsevier B.V. Retrieved from http://dx.doi.org/10.1016/j.gecco.2014.12.008

Martins, F. O., \& Langeani, F. (2016). Redescription of Hisonotus notatus Eigenmann \& Eigenmann, 1889 (Loricariidae: Hypoptopomatinae), The type species of the genus, and description of a new species from coastal drainages of southeastern Brazil. Neotropical Ichthyology, 14(2), 1-18.

Matthews-Cascon, H., Bezerra, L. E. A., Barroso, C. X., Rabay, S. G., Moreira, A. K., Rocha, V. P., \& Soares, M. de O. (2018). Marine benthic communities affected by the Doce River (southwestern Atlantic): Baseline before a mining disaster. Marine Pollution Bulletin, 135.

Merigó, J. M., Pedrycz, W., Weber, R., \& de la Sotta, C. (2018). Fifty years of Information Sciences: A bibliometric overview. Information Sciences, 432, 245-268.

Mishra, D., Gunasekaran, A., Papadopoulos, T., \& Childe, S. J. (2016). Big Data and supply chain management: a review and bibliometric analysis. Annals of Operations Research, 270(12), 313-336.

Myers, N., Mittermeier, R. a, Mittermeier, C. G., da Fonseca, G. a, \& Kent, J. (2000). Biodiversity hotspots for conservation priorities. Nature, 403(6772), 853-8. Retrieved from http://www.ncbi.nlm.nih.gov/pubmed/10706275

Oliveira, J. C., \& Oyakawa, O. T. (2019). New loricariid fishes from headwaters on Serra da

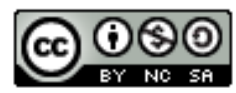

Esta obra está licenciada com uma Licença Creative Commons Atribuição-Não Comercial-Compartilha Igual 4.0 Internacional. Brazilian Journal of Production Engineering, São Mateus, Editora UFES/CEUNES/DETEC. 
Mantiqueira and Complexo do Espinhaço, Minas Gerais State, Brazil (teleostei: Siluriformes: Loricariidae). Zootaxa, 4586(3), 401-424.

Oliveira, P. D. C., Di Beneditto, A. P. M., Quaresma, V. da S., Bastos, A. C., \& Zappes, C. A. (2020). Traditional knowledge of Fishers versus an environmental disaster from mining waste in Central Brazil. Marine Policy, 120, 104129. Retrieved from http://www.sciencedirect.com/science/article/pii/S0308597X20301585

Ottoni, F. P. (2010). Australoheros capixaba, a new species of Australoheros from southeastern Brazil (Labroidei: Cichlidae: Cichlasomatinae). Vertebrate Zoology, 60(1), 19-25. Retrieved from http://cichlidae.us/wp-content/uploads/pdf/Australoheros capixaba.pdf

Oyakawa, O. T., \& Mattox, G. M. T. (2009). Revision of the Neotropical trahiras of the Hoplias lacerdae species-group (Ostariophysi: Characiformes: Erythrinidae) with descriptions of two new species. Neotropical Ichthyology, 7(2), 117-140.

Paiva, S. R., Dergam, J. A., \& Machado, F. (2006). Determining management units in southeastern Brazil: The case of Astyanax bimaculatus (Linnaeus, 1758) (Teleostei: Ostariophysi: Characidae). Hydrobiologia, 560(1), 393-404.

Passos, L. S., Gnocchi, K. G., Pereira, T. M., Coppo, G. C., Cabral, D. S., \& Gomes, L. C. (2020). Is the Doce River elutriate or its water toxic to Astyanax lacustris (Teleostei: Characidae) three years after the Samarco mining dam collapse? Science of the Total Environment, 736.

Pereira, E. H. L., \& Britto, M. R. (2012). A New Distinctively Colored Catfish of the Genus Pareiorhaphis (Siluriformes: Loricariidae) from the Rio Piracicaba, Upper Rio Doce Basin, Brazil. Copeia, (3), 519-526.

Pereira, E. H. L., Pablo, L. A., \& Reis, R. E. (2012). A new species of the neoplecostomine catfish Pareiorhaphis (Siluriformes: Loricariidae) from the coastal basins of Espírito Santo, eastern Brazil. Neotropical Ichthyology, 10(3), 539-546.

Pereira, E. H. L., Vieira, F., \& Reis, R. E. (2007). A new species of sexually dimorphic Pareiorhaphis Miranda Ribeiro, 1918 (Siluriformes: Loricariidae) from the rio Doce basin, Brazil. Neotropical Ichthyology, 5(4), 443-448.

Pereira, E. H. L., Vieira, F., \& Reis, R. E. (2010). Pareiorhaphis scutula, a new species of neoplecostomine catfish (Siluriformes: Loricariidae) from the upper rio Doce basin, Southeastern Brazil. Neotropical Ichthyology, 8(1), 33-38.

Pinheiro, H. T., \& Joyeux, J.-C. (2007). Pescarias multi-específicas na região da foz do Rio Doce, ES, Brasil: características, problemas e opções para um futuro sustentável. Brazilian Journal of Aquatic Science and Technology, 11(2), 15-23.

Pinto-Coelho, R. M., Bezerra-Neto, J. F., Miranda, F., Mota, T. G., Resck, R., Santos, A. M., Maia-Barbosa, P. M., et al. (2008). The inverted trophic cascade in tropical plankton communities: Impacts of exotic fish in the Middle Rio Doce lake district, Minas Gerais, Brazil. Brazilian Journal of Biology, 68(4), 1025-1037.

Reis, V. J. C., de Pinna, M. C. C., \& Pessali, T. C. (2019). A new species of Trichomycterus Valenciennes 1832 (Trichomycteridae: Siluriformes) from the Rio Doce drainage with remarkable similarities with Bullockia and a CT-scan survey. Journal of Fish Biology, 95(3), 918-931.

Rocha, K. S., Santos, C. T., \& Freitas, R. R. De. (2018). Diagnóstico da Atividade Pesqueira no Espírito Santo, Brasil: um Estudo sobre o Segmento de Peixarias. Revista Brasileira de Engenharia de Pesca, 11(1), 97-112.

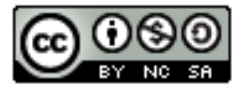


Rosa, R. S., \& Menezes, N. A. (1996). Relação preliminar das espécies de peixes (Pisces, Elasmobranchii, Actinopterygii) ameaçadas no Brasil. Revista Brasileira de Zoologia, 13(3), 647-667.

Roxo, F. F., Silva, G. S. C., Zawadzki, C. H., \& Oliveira, C. (2014). Neoplecostomus doceensis: A new loricariid species (Teleostei, Siluriformes) from the rio doce basin and comments about its putative origin. ZooKeys, 440, 115-127.

Salvador, G. N., Frederico, R. G., Pessali, T. C., Vieira, F., \& Freitas, T. M. S. (2018). Lengthweight relationship of 21 fish species from Rio Doce River basin, Minas Gerais, Brazil. Journal of Applied Ichthyology, 34, 1198-1201.

Santos, O., \& Castro, R. M. C. (2014). Taxonomy of Probolodus Eigenmann, 1911 (Characiformes: Characidae) with description of two new species, and comments about the phylogenetic relationships and biogeography of the genus. Neotropical Ichthyology, 12(2), 403-418.

Sarmento-Soares, L. M., \& Martins-Pinheiro, R. F. (2013). Glanidium botocudo, a new species from the rio Doce and rio Mucuri, Minas Gerais, Brazil (Siluriformes: Auchenipteridae) with comments on taxonomic position of Glanidium bockmanni Sarmento-Soares \& Buckup. Neotropical Ichthyology, 11(2), 265-274.

Silva, P. C., Malabarba, M. C., \& Malabarba, L. R. (2017). Using ancient DNA to unravel taxonomic puzzles: The identity of Deuterodon pedri (Ostariophysi: Characidae). Neotropical Ichthyology, 15(1), 1-12.

Silva, P. C., Santos, U., Travenzoli, N. M., Zanuncio, J. C., de Cioffi, M. B., \& Dergam, J. A. (2012). The unique karyotype of Henochilus wheatlandii, a critically endangered fish living in a fast-developing region in Minas Gerais State, Brazil. PLoS ONE, 7(7), 1-5.

Teixeira, J. B., Lima, A. C., Boechat, F. P., Rodrigues, R. L., \& Freitas, R. R. (2012). Potencialidade social e econômica da pesca e maricultura no Estado do Espírito Santo, Brasil. Revista de Gestão Costeira Integrada, 12(4), 569-575.

Trindade-Santos, I., Eduardo, A. A., Moyes, F., Martinez, P. A., Magurran, A. E., \& Gouveia, S. F. (2018). Simulating shifts in taxonomic and functional $\beta$-diversity of ray-finned fishes: Probing the Mariana disaster. Perspectives in Ecology and Conservation, 16(4), 186-192. Associação Brasileira de Ciência Ecológica e Conservação. Retrieved from https://doi.org/10.1016/j.pecon.2018.09.002

Urquiza, A. H. A., \& Rocha, A. de O. (2019). O Desastre Ambiental de Mariana e os Krenak do Rio Doce. Veredas dos Direito, 16(35), 191-218.

Viana, J. P. (2017). Os pescadores da bacia do Rio Doce: subsídios para a mitigação dos impactos socioambientais do desastre da Samarco em Mariana, Minas Gerais. Boletim regional, urbano e ambiental, (16), 1-51. Retrieved from http://www.ipea.gov.br

Vono, V., \& Barbosa, F. A. R. (2001). Habitats and littoral zone fish community structure of two natural lakes in southeast Brazil. Environmental Biology of Fishes, 61(4), 371-379.

Weber, A. A., Sales, C. F., de Souza Faria, F., Melo, R. M. C., Bazzoli, N., \& Rizzo, E. (2020). Effects of metal contamination on liver in two fish species from a highly impacted neotropical river: A case study of the Fundão dam, Brazil. Ecotoxicology and Environmental Safety, 190(October 2019). 